This PDF is a selection from an out-of-print volume from the National Bureau of Economic Research

Volume Title: The State of Monetary Economics

Volume Author/Editor: Universities-National Bureau Committee for Economic Research

Volume Publisher: NBER

Volume ISBN: 0-87014-307-7

Volume URL: http://www.nber.org/books/univ65-1

Publication Date: 1965

Chapter Title: Money and Business Cycles

Chapter Author: Milton Friedman, Anna J. Schwartz

Chapter URL: http://www.nber.org/chapters/c5179

Chapter pages in book: (p. 32 - 78) 


\title{
MONEY AND BUSINESS CYCLES
}

\author{
Milton Friedman and Anna J. Schwartz \\ University of Chicago and National Bureau of Economic Research
}

$\mathrm{T}$ HE subject assigned for this session covers too broad an area to be given even a fairly cursory treatment in a single paper. Accordingly, we have chosen to concentrate on the part of it that relates to monetary factors in economic fluctuations. We shall still further narrow the scope of the paper by interpreting "monetary factors" to mean the role of the stock of money and of changes in the stock thereby casting the "credit" market as one of the supporting players rather than a star performer - and by interpreting "economic fluctuations" to mean business cycles, or even more exactly, the reference cycles studied and chronicled by the National Bureau.

The topic so interpreted has been rather out of fashion for the past few decades. Before the Great Depression, it was widely accepted that the business cycle was a monetary phenomenon, "a dance of the dollar," as Irving Fisher graphically described it in the title of a famous article. $^{1}$ Different versions of monetary theories of the business cycle abounded, though some of these were really "credit" theories misnamed, since they gave little role to changes in the money stock except as an incident in the alteration of credit conditions; and there was nothing like agreement on the details of any one theory. Yet it is probably true that most economists gave the money stock and changes in it an important, if not a central, role in whatever particular theory of the cycle they were inclined to accept. That emphasis was greatly strengthened by the course of economic events in the twenties. The high degree of economic stability then achieved was widely regarded as a consequence of the effectiveness of the monetary policies followed by the only recently created Federal Reserve System and hence as evidence that monetary factors were indeed a central factor in the cycle.

The Great Depression radically changed economic attitudes. The failure of the Federal

\footnotetext{
1 "The Business Cycle Largely a "Dance of the Dollar," Journal of the American Statistical Association, December r923, pp. 1024-I028.
}

Reserve System to stem the depression was widely interpreted - wrongly as we have elsewhere argued $^{2}$ and elaborate below - to mean that monetary factors were not critical, that "real" factors were the key to economic fluctuations. Investment - which had always had a prominent place in business cycle theories received new emphasis as a result of the Keynesian revolution, so much so that Paul Samuelson, in the best selling textbook in the country, could assert confidently, "All modern economists are agreed that the important factor in causing income and employment to fluctuate is investment." 3 Investment was the motive force, its effects spread through time and amplified by the "multiplier," and itself partly or largely a result of the "accelerator." Money, if it entered at all, played a purely passive role.

Recently, a revival of interest in money has been sparked less by concern with business cycles than with concern about inflation. Easy money policies were accompanied by inflation; and inflation was nowhere stemmed without a more or less deliberate limitation of growth of the money stock. But once interest was aroused, it naturally extended to the cycle as well as to inflation. In the United States, indeed, there has been something of a repetition of the I920's. A high degree of economic stability has been accompanied by a large measure of talk about an active monetary policy, and the monetary authorities have often been given credit for playing an important role in promoting stability. As the experience of the twenties suggests, this fair-weather source of support for the importance of money is a weak reed.

Examining the present state of our understanding about the role of money in the business cycle, we shall first present some facts that seem reasonably well established about the cyclical behavior of money and related

\footnotetext{
${ }^{2}$ See our forthcoming "A Monetary History of the United States, 1867-1960" (in press, I963), Chapter 7.

${ }^{3}$ Economics, 3rd ed., 1955, p. 224
} 
Chart 1. - Money Stock Including Commercial Bank Time Deposits, i867-ig6o, and Currency Plus Demand Deposits Adjusted, r9l4-rg6o

Currency held by the public, plus demand deposits ajjusted, plus commercial bank time deposits

- - Currency held by the public, plus demand deposits adjusted
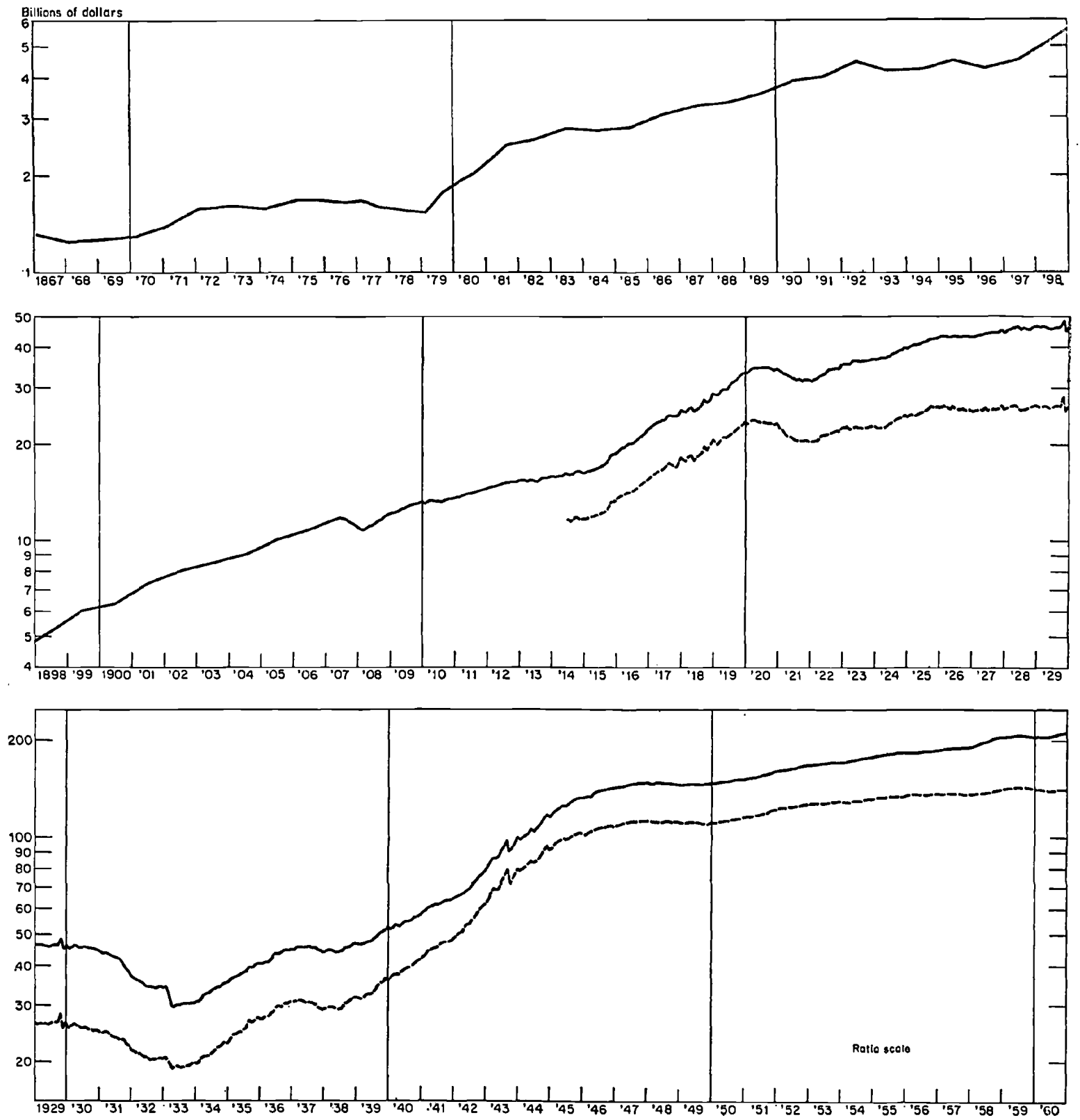

Source: Friedman and Schwartz, "A Monetary History of the United States, 1867-1960" (in press, 1963), Table A-1, cols. 7 and 8. These are seasonally adjusted figures, dated as of end of month, 1867-1946; for $1947-60$, currency plus demand deposits adjusted is an average of daily figures, and commercial bank time deposits, a 2 -month moving average of last-Wednesday-of-month figures, for a month centered at midmonth. 
magnitudes and then speculate about some plausible interpretations of these facts. The facts we present are drawn largely from our own unpublished work done under the auspices of the National Bureau of Economic Research and associated unpublished work by Phillip Cagan.

\section{Some Facts About the Cyclical Behavior of Money}

\section{Cyclical pattern of the money stock.}

The outstanding cyclical fact about the stock of money is that it has tended to rise during both cyclical expansions and cyclical contractions. This is clear from Chart I, which plots (I) the stock of money from I 867 to I960, with money defined as including currency plus adjusted deposits in commercial banks (both demand and time) held by the nonbanking public (i.e., excluding both balances of the federal government and of banks); and (2) from I9I4 on, a narrower total which excludes time deposits. From $\mathrm{I}^{867}$ to I907, our data are at annual or semiannual dates; from 1907 on, monthly. The only major exceptions since I 867 to the tendency of the money stock to rise during both cyclical expansions and cyclical contractions occurred in the years listed in the following tabulation, which gives also the percentage decline during each exception.

$\begin{array}{cc}\begin{array}{c}\text { Years of } \\ \text { Exception }\end{array} & \begin{array}{c}\text { Percentage } \\ \text { Decline }\end{array} \\ \text { I } 873-79 & 4.9 \\ \text { I892-94 } & 5.8 \\ \text { I907-08 } & 3.7 \\ \text { I920-2 I } & 5 . \mathrm{I} \\ \text { I929-33 } & 35.2 \\ \text { I937-38 } & 2.4\end{array}$

In addition, there were two minor exceptions since the end of World War II,

$\begin{array}{ll}\text { I } 948-49 & \text { I.4 } \\ \text { I } 959-60 & \text { I.I }\end{array}$

The major exceptions clearly did not fall in a random subset of years. Each corresponds with an economic contraction that was major as judged by other indicators; in the period covered, there was no other economic contraction more severe than any in the list; and there appears to be a considerable gap between the severity of those contractions and of the re- mainder, with the possible exception of the contraction of $1882-85$ which might be regarded as a somewhat borderline case.

For mild depression cycles, therefore, the cycle does not show up as a rise and a fall. Chart 2 gives the average reference-cycle pat-

Chart 2. - Money Stock: Average Reference-Cycle Patterns for Mild and Deep Depression Cycles, I867-I96I

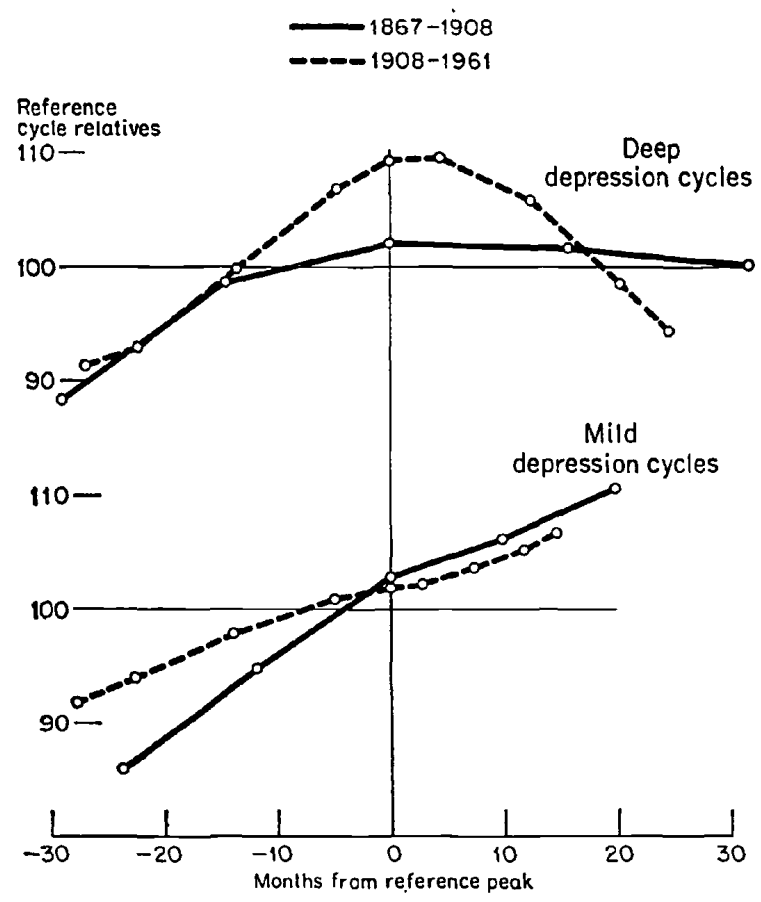

Note: War cycles, not shown, are 1914-19 and 1938-45. Deep depression cycles are $1870-79,189 x-94,1904-08,1919-21,1927-33$ and 1933-38. All others are mild depression cycles.

Source: For method of deriving reference cycle relatives for the 9point pattern, see A. F. Burns and W. C. Mitchell, Measuring Business Cycles, National Bureau of Economic Research, 1946 pp 160-170; we used a variant of the National Bureau's standard technique for annual series (pp. 197-202) for the 5-point pattern.

terns for mild and deep depression cycles since r 867 , excluding only war cycles. (Patterns are given separately for the period before and after I907, because the availability of monthly data after 1907 permits the construction of a more detailed pattern - a nine-point instead of a five-point pattern.) The patterns for mild depression cycles rise almost in a straight line, though there is some indication of a slower rate of growth from mid-expansion to mid-contraction than during the rest of the cycle (especially in the nine-point pattern for monthly data). In its cyclical behavior, the money stock is like other series with a sharp upward 
trend - such as population, the total stock of houses, the number of miles of railroad track in operation in the pre-1914 period, the amount of electrical energy produced. In all of these, the cycle shows up not in an absolute rise and fall but in different rates of rise.

For deep depression cycles, the cyclical pattern is nearer the stereotype of a rise during expansion and a fall during contraction. From these patterns, it would be easy to conclude that the two groups of cycles distinguished are members of different species with respect to the behavior of the stock of money.

\section{Cyclical pattern of the rate of change in the money stock.}

Because the strong upward trend of the stock of money tends to dominate its cyclical

Chart 3. - Month-to-Month Rate of Change in U.S. Money Stock, I867-1960
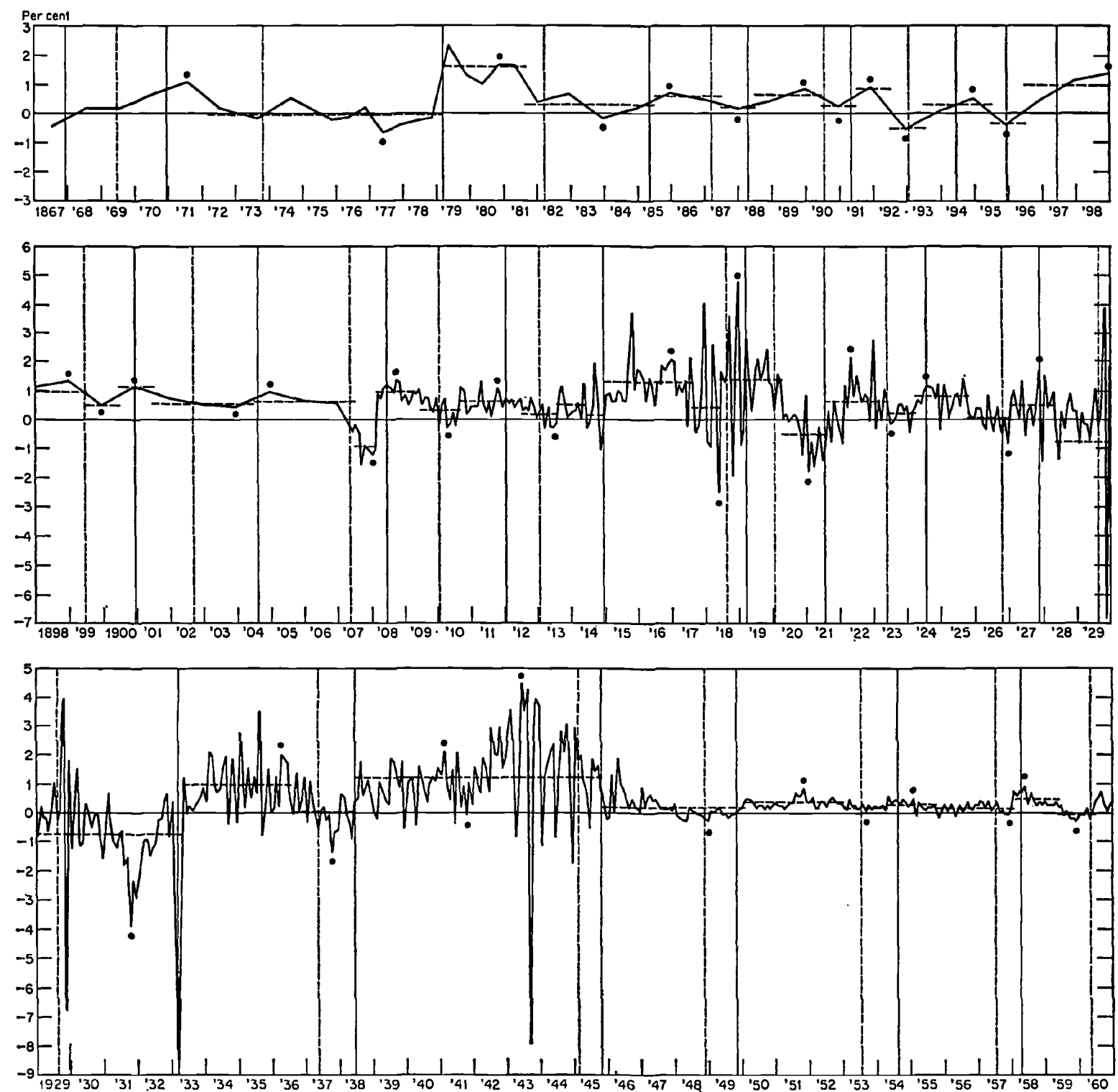

Note: Solid vertical lines represent reference cycle troughs; broken lines, peaks. Dots represent peaks and troughs of specific cycles. The horizontal broken lines represent bigh and low steps in the rate of change.
Source: In the annual or semiannual segment, $1867-1907$, the change in natural logarithm from one date to the next in the data underlying Chart I was divided by the number of months intervening, and the quotient plotted at the middle of the month halfway between. In the monthly segment, 1907-60, the month-to-month change in natural logarithm was plotted in the middle of the second month. Reference dates are from the National Bureau (see Table I). 
behavior, it is desirable to eliminate the effect of the trend in order to reveal the cyclical behavior more clearly. There are various ways of doing this. ${ }^{4}$ The method we have used is to take logarithmic first differences of the money stock, which is equivalent to using the percentage rate of change from one time unit to the next. Chart 3 plots the resulting series. It is clear that this device effectively eliminates trend. It is clear also that, as first differencing usually does, it produces a highly jagged series with a sawtooth appearance. The reason is that independent errors of measurement in the original stock series introduce negative serial correlation into first differences. But despite these short-term irregularities, the series shows clearly marked cyclical fluctuations corresponding to reference cycles.

Chart 4 gives the reference cycle patterns for this series. They show a clear cyclical pattern with the mild and deep depression cycles distinguished, this time primarily by their amplitude, so that they now look more like different members of the same species. The peak rate of change occurs early in expansion and the trough early in recession. Indeed these occur so early as to suggest the possibility of interpreting the rate of change series as inverted, i.e., as generally declining during reference expansion and rising during reference contraction. We have examined this possibility elsewhere. ${ }^{5}$ A full presentation of our tests is

"See the discussion of this problem in Milton Friedman, "The Lag in Effect of Monetary Policy," Journal of Political Economy, October I 96r, pp. 453-454.

${ }^{5}$ See our forthcoming "Trends and Cycles in the Stock of Money in the United States, $1867-1960 . "$

The patterns in Chart 4 differ in construction from the reference patterns for the stock of money in Chart 2. The rate of change series, being the percentage change from month to month, is already in a form that is independent of units of measure. In addition, the rate of change in the money stock can be zero or negative as well as positive, and hence its average value for a given cycle can hardly serve as a base for computing reference cycle relatives. For these reasons, the basic data, instead of being expressed as relatives to the average for a cycle, are expressed as deviations from the average for a cycle (as in A. F. Burns and W. C. Mitchell, Measuring Business Cycles, New York, NBER, r 946, pp. $137-\mathrm{r}_{38}$ ). This is why the base lines in Chart 4 are labeled 0 instead of roo as in Chart 2 , and the scale is in terms of deviations rather than of relatives.

Because of a discontinuity in the underlying money figures in early 1933, we have estimated stage IX for the $1927-33$ cycle and stage $I$ for the $1933-38$ cycle from the average not feasible in this paper; it will suffice to note that they rather decisively support treating the rate of change series as conforming to the reference cycle positively with a long lead, rather

Chart 4. - Rate of Change in Money Stock: Average Reference-Cycle Patterns for Mild and Deep Depression CyCles, I $867-196 \mathrm{I}$
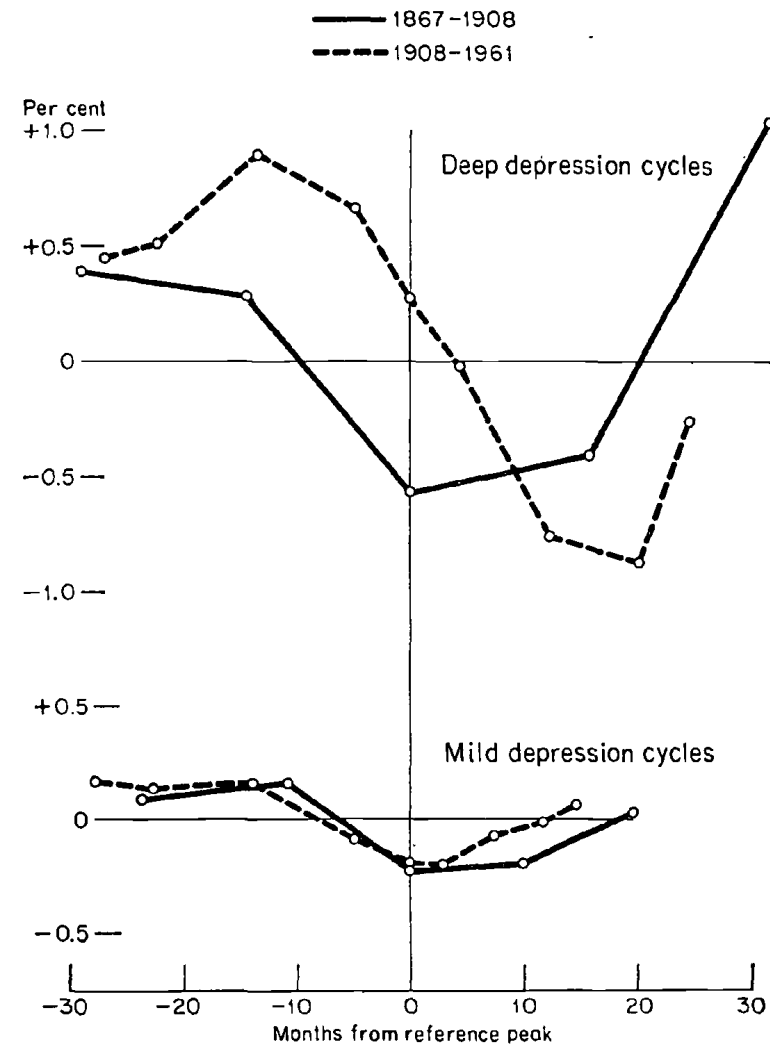

Note: War cycles, not shown, are $1914-19$ and $1938-45$. Deep depression cycles are $1870-79$, 1891-94, 1904-08, 1919-21, 1927-33, and 1933-38. All others are mild depression cycles. Source: See footnote 5 .

than inversely with a somewhat shorter lag. Though we have not analyzed in as much detail the narrower total of currency plus adjusted demand deposits, its cyclical pattern since I9I4 is very similar in general form to the pattern of the broader total.

value for January, April, and May, 1933, instead of for February, March, and April. Restricted deposits before the banking holiday are counted in full in the recorded money stock. However, after the holiday both restricted and unrestricted deposits in unlicensed banks are excluded completely from the recorded money stock. That shift in treatment is the major factor behind the sharp decline in the recorded figures in March I933 (see our "A Monetary History of the United States, 1867-1960," Chapter 8, section $\mathbf{r}$ ). 
Cyclical timing of the rate of change in the money stock.

Evidence on cyclical timing derived from a comparison of turning points is clearly not available from the stock of money series, because it has so few turning points. For the rate-of-change series, we have dated turning points in two ways: ( I) We have sought to approximate the series by a step function, with successively high and low steps, because at times the series gives the impression of drop- a low step ends, the date of a step trough. (2) We have applied the usual National Bureau specific cycle dating procedure to the rate-ofchange series, and have designated specific cycle peaks and troughs. They are marked by black dots in Chart 3 .

Table I gives the step and specific cycle peaks and troughs we have selected, the dates of the reference cycle turns with which we have matched them, and the indicated lead $(-)$ or lag $(+)$ at the corresponding turn. ${ }^{8}$

Table i. - Timing of Specific Cycle and of Step Troughs and Peaks in the Rate of Change in the Money Stock Compared with Timing of Business Cycles

\begin{tabular}{|c|c|c|c|c|c|c|c|c|c|}
\hline \multicolumn{5}{|c|}{ TROUGHS } & \multicolumn{5}{|c|}{ PEAKS } \\
\hline \multirow[b]{2}{*}{$\begin{array}{c}\text { Step }^{\circ} \\
\text { Trough }\end{array}$} & \multicolumn{2}{|l|}{ Date of: } & \multicolumn{2}{|c|}{$\begin{array}{l}\text { Lead }(-) \text { or } \operatorname{Lag}(+) \text { in } \\
\text { Months at Reference } \\
\text { Trough of: }\end{array}$} & \multicolumn{3}{|c|}{ Date of: } & \multicolumn{2}{|c|}{$\begin{array}{c}\text { Lead }(-) \text { or } \operatorname{Lag}(+) \text { in } \\
\text { Months at Reference } \\
\text { Peak of: }\end{array}$} \\
\hline & $\begin{array}{l}\text { Specific } \\
\text { Cycle } \\
\text { Trough }\end{array}$ & $\begin{array}{l}\text { Matched } \\
\text { Reference } \\
\text { Trough }\end{array}$ & $\underset{\text { Trough }}{\text { Step }}$ & $\begin{array}{c}\text { Specific } \\
\text { Cycle Trough }\end{array}$ & $\begin{array}{l}\text { Step } \\
\text { Peak }\end{array}$ & $\begin{array}{l}\text { Specific } \\
\text { Cycle } \\
\text { Peak }\end{array}$ & $\begin{array}{l}\text { Matched } \\
\text { Reference } \\
\text { Peak }\end{array}$ & $\begin{array}{c}\text { Step } \\
\text { Peak }\end{array}$ & $\begin{array}{c}\text { Specific } \\
\text { Cycle Peak }\end{array}$ \\
\hline \multicolumn{10}{|c|}{ SEMIANNUAL AND ANNUAL DATA } \\
\hline & & & & & $2 / 72$ & $7 / 71$ & $10 / 73$ & -20 & -27 \\
\hline $2 / 79$ & $5 / 77$ & $3 / 79$ & -1 & -22 & $8 / 8 \mathrm{I}$ & $5 / 8 \mathrm{r}$ & $3 / 82$ & -7 & -10 \\
\hline $6 / 85$ & $12 / 83$ & $5 / 85$ & $+\mathrm{I}$ & $-\mathrm{r} 7$ & $6 / 87$ & $12 / 85$ & $3 / 87$ & +3 & -15 \\
\hline $6 / 88$ & $12 / 87$ & $4 / 88$ & +2 & -4 & $6 / 90$ & $12 / 89$ & $7 / 90$ & $-I$ & -7 \\
\hline $6 / 9 I$ & $12 / 90$ & $5 / 91$ & $+I$ & -5 & $6 / 92$ & $12 / 91$ & $1 / 93$ & -7 & -13 \\
\hline $6 / 93$ & $12 / 92$ & $6 / 94$ & -12 & -18 & $6 / 95$ & I $2 / 94$ & $12 / 95$ & -6 & -12 \\
\hline $6 / 96$ & $12 / 95$ & $6 / 97$ & -12 & -18 & $6 / 99$ & $12 / 98$ & $6 / 99$ & 0 & -6 \\
\hline $6 / 00$ & $12 / 99$ & $12 / 00$ & -6 & -12 & $6 / 01$ & $12 / 00$ & $9 / 02$ & -15 & $-2 \mathrm{I}$ \\
\hline $6 / 0_{4}$ & $12 / 03$ & $8 / 04$ & -2 & -8 & $6 / 07$ & $12 / 04$ & $5 / 07$ & $+\mathbf{r}$ & -29 \\
\hline \multicolumn{10}{|c|}{ MONTHLY DATA } \\
\hline $2 / 08$ & I/08 & $6 / 08$ & -4 & -5 & $6 / 09$ & $10 / 08$ & I/10 & -7 & -15 \\
\hline $8 / 10$ & $4 / 10$ & $\mathrm{I} / \mathrm{I} 2$ & -17 & $-2 \mathbf{I}$ & $6 / 12$ & $10 / 11$ & $1 / 13$ & -7 & -15 \\
\hline $7 / 13$ & & & & & $5 / 14$ & & & & \\
\hline $12 / 14$ & $6 / 13$ & $12 / 14$ & 0 & -18 & $7 / 17$ & $12 / 16$ & $8 / 18$ & -13 & -20 \\
\hline $5 / 18$ & $5 / 18$ & $3 / 19$ & - I0 & -10 & $3 / 20$ & $12 / 18$ & $1 / 20$ & +2 & -13 \\
\hline $7 / 21$ & $\mathrm{I} / 2 \mathrm{I}$ & $7 / 21$ & 0 & -6 & $5 / 23$ & $4 / 22$ & $5 / 23$ & 0 & -13 \\
\hline $3 / 24$ & $6 / 23$ & $7 / 24$ & -4 & -13 & $9 / 25$ & $7 / 24$ & $10 / 26$ & -13 & -27 \\
\hline $12 / 26$ & $12 / 26$ & II $/ 27$ & $-I I$ & $-I I$ & $4 / 28$ & $11 / 27$ & $8 / 29$ & -16 & $-2 \mathrm{I}$ \\
\hline $4 / 33$ & $10 / 31$ & $3 / 33$ & $+I$ & -17 & $7 / 36$ & $4 / 36$ & $5 / 37$ & -10 & -13 \\
\hline \multirow[t]{3}{*}{$5 / 38$} & $10 / 37$ & $6 / 38$ & $-I$ & -8 & & $2 / 4 \mathrm{I}$ & & & \\
\hline & $10 / 4 \mathrm{I}$ & & & & $10 / 45$ & $6 / 43$ & $2 / 45$ & +8 & -20 \\
\hline & & $10 / 45$ & & & & & $11 / 48$ & & \\
\hline $1 / 50$ & $x / 49$ & $10 / 49$ & +3 & -9 & $12 / 52$ & I $1 / 51$ & $7 / 53$ & -7 & -20 \\
\hline $4 / 54$ & $9 / 53$ & $8 / 54$ & -4 & $-\mathbf{I I}$ & $9 / 55$ & $2 / 55$ & $7 / 57$ & -22 & -29 \\
\hline $1 / 58$ & $12 / 57$ & $4 / 58$ & -3 & -4 & $5 / 59$ & $6 / 58$ & $5 / 60$ & -12 & -23 \\
\hline $6 / 60$ & $12 / 59$ & $2 / 6 I$ & -8 & -14 & & & & & \\
\hline
\end{tabular}

Source: Chart 3. Step peaks and step troughs are last months of alternate steps shown there.

Reference dates through Apr. 1958 are shown in Business Cycle Indicators, Geoffrey H. Moore, ed., Princeton University Press for NBER, I961, Vol. I, p. 670; subsequent dates are from an unpublished National Bureau table. For timing comparisons, both the rate of change series and the steps made from it are treated as well conforming, because of the nearly 1 -to-r correspondence between their turning points and reference cycle turning points, and because the money stock series from which both were derived has moderately high conformity indexes (100 for expansions, -43 for contractions, +71 for trough-to-trough full cycles, +50 for peak-to-peak full cycles, +61 for full cycles
both ways). Matching of step and specific cycle turns with reference turns follows Burns and Mitchell, Measuring Business $C y c l e s$, pp. I $5-128$. both ways). Matching of step and specific cycle turns with referem

ping suddenly from one level to a decidedly lower level, or of rising from one level to a decidedly higher level. The horizontal broken lines in Chart 3 indicate the steps we have used. We call the date at which a high step ends, the date of a step peak, the date at which
- Though our money series starts in 1867 , the first reference turn with which we have matched a specific cycle turn is the peak in October 1873 . Hence we do not match the reference trough of December 1867 , peak of June 1869 , and trough of December 1870 . The absence of a specific cycle turn to match with the December 1867 trough may simply result from the fact that our series does not go far enough back in time - a possibility suggested by the long average 
Clearly, leads predominate, and clearly also, there is much variability.

Table 2 gives the average lead and the standard deviations of the leads for mild depression cycles, deep depression cycles, all nonwar cycles and all cycles, for both step dates and specific cycle dates. For step dates, the aver- ticular, cross-correlograms and cross-spectral analysis. While these devices, particularly cross-spectral analysis, offer great promise for the future, as yet we have no substantive results worth reporting.

We have tested to determine whether there is any secular trend in the leads or lags; whether

Table 2.- Average Timing of Specific Cycle and of Step Peaks and Troughs in the Rate of Change in the Money Stock and Standard Deviation of Lead or Lag, by Period and Type of Cycle

\begin{tabular}{|c|c|c|c|c|c|c|c|c|c|c|c|c|}
\hline \multirow[b]{3}{*}{ Period } & \multicolumn{4}{|c|}{ NUMBER OF OBSERVATIONS } & \multicolumn{4}{|c|}{ MEAN LEAD ( $(-)$ OR LAG (+) IN MONTHS } & \multicolumn{4}{|c|}{$\begin{array}{l}\text { STANDARD DEVIATION OF } \\
\text { LEAD OR LAG IN MONTHS }\end{array}$} \\
\hline & \multicolumn{2}{|c|}{ Step Analysis } & \multicolumn{2}{|c|}{$\begin{array}{c}\text { Specific Cycle } \\
\text { Analysis }\end{array}$} & \multicolumn{2}{|c|}{ Step Analysis } & \multicolumn{2}{|c|}{$\begin{array}{l}\text { Specific Cycle } \\
\text { Analysis }\end{array}$} & \multicolumn{2}{|c|}{ Step Analysis } & \multicolumn{2}{|c|}{$\begin{array}{l}\text { Specific Cycle } \\
\text { Analysis }\end{array}$} \\
\hline & Trough & Peak & Trough & Peak & Trough & Peak & Trough & Peak & Trough & Peak & Trough & Peak \\
\hline \multicolumn{13}{|c|}{ ALL CYCLES } \\
\hline I870-1908 & 8 & 9 & 8 & 9 & -3.6 & -5.8 & -13.0 & -15.6 & 5.7 & 7.7 & 6.7 & 8.3 \\
\hline $1908-1960$ & 13 & 12 & 13 & 12 & -4.5 & -8.1 & -11.3 & -19.1 & 5.7 & 8.3 & 5.2 & 5.5 \\
\hline $1870-1960$ & $2 \mathrm{I}$ & $2 \mathbf{I}$ & 21 & 21 & $-4 \cdot \mathrm{I}$ & -7.1 & -12.0 & -17.6 & 5.6 & 7.9 & 5.7 & 6.9 \\
\hline \multicolumn{13}{|c|}{ WAR CYCLES } \\
\hline I908-1960 & $\mathbf{I}$ & 2 & $\mathbf{I}$ & 2 & -10.0 & -2.5 & -10.0 & -20.0 & - & $\mathbf{I} 4.8$ & - & $\circ$ \\
\hline \multicolumn{13}{|c|}{ DEEP DEPRESSION CYCLES } \\
\hline $1870-1908$ & 2 & 3 & 2 & 3 & -6.5 & -8.7 & -20.0 & -23.0 & 7.8 & 10.6 & 2.8 & 8.7 \\
\hline $1908-1960$ & 4 & 3 & 4 & 3 & -1.0 & -8.0 & -9.0 & -15.7 & 2.2 & 9.2 & 5.5 & 4.6 \\
\hline $1870-1960$ & 6 & 6 & 6 & 6 & -2.8 & -8.3 & -12.7 & -19.3 & 4.8 & 8.9 & 7.2 & 7.4 \\
\hline \multicolumn{13}{|c|}{ MILD DEPRESSION CYCLES } \\
\hline $1870-1908$ & 6 & 6 & 6 & 6 & -2.7 & -4.3 & -10.7 & $-\mathbf{I} \mathbf{1} 8$ & 5.4 & 6.4 & 6.0 & 5.6 \\
\hline $1908-1960$ & 8 & 7 & 8 & 7 & $-5 \cdot 5$ & -9.7 & -12.6 & -20.3 & 6.3 & 6.9 & 5.3 & 6.3 \\
\hline $1870-1960$ & 14 & I3 & I4 & 13 & -4.3 & -7.2 & $-\mathrm{Ir} .8$ & -16.4 & 5.9 & 7.0 & 5.5 & 7.2 \\
\hline
\end{tabular}

depression cycles are grouped as in Chart 2.

age lead for all cycles is 7 months at the peak and 4 months at the trough; for specific cycle dates, the average lead is 18 months at the peak and 12 months at the trough; for step dates, the standard deviation of the lead is 6 months at troughs and 8 months at peaks; for specific cycle dates, the standard deviation of the lead is 6 months at troughs and 7 months at peaks.

Estimation of timing relations by a comparison of turning points seems inefficient, because it uses so little of the information contained in the series. Therefore, we have experimented extensively with other devices, in par-

lead at troughs. For the other two reference turns, we conjecture that the annual data for successive Januarys - all we have for that period - may conceal by their crudeness turns that monthly data would reveal. This conjecture seems especially plausible because of the unusual brevity of the expansion phase, only 18 months, followed by a contraction of equal length. the pre-I9I4 timing, before the establishment of the Federal Reserve System, differs from the post-IgI4 timing; whether timing during mild depression cycles differs from timing during deep depression cycles; and whether there is any relation between the length of the lead and the amplitude of the subsequent or prior cyclical phase. Our results so far are negative: none of these criteria appears to be associated with a statistically significant difference in timing.

\section{Amplitude of movements in the rate of change in the money stock.}

I. The subdivision between mild and severe depression cycles in Chart 4 corresponds to a sharp difference in the amplitude of reference cycles in the rate of change. This result suggests that the amplitude of the changes in the rate of change in the money stock is related to 
Table 3. - Rank Difference Correlation Between Change in Rate of Change in Money Stock and Change in Two Indicators of General Business, I879-I96I, ExCluding War CyCles AND $1945-49$

\begin{tabular}{|c|c|c|c|c|}
\hline \multirow[b]{3}{*}{$\begin{array}{l}\text { Specific Cycles in Rate of } \\
\text { Change in Money Stock } \\
\text { Correlated with: }\end{array}$} & \multicolumn{4}{|c|}{$\begin{array}{l}\text { RANK DIFFERENCE CORRELATION } \\
\text { OF AMPLITUDES }\end{array}$} \\
\hline & \multicolumn{2}{|c|}{ NBER Reference } & \multicolumn{2}{|c|}{$\begin{array}{l}\text { NBER Reference } \\
\text { Full Cycle } \\
\end{array}$} \\
\hline & $\begin{array}{c}\text { Expan- } \\
\text { sion }\end{array}$ & $\begin{array}{c}\text { Contrac- } \\
\text { tion }\end{array}$ & $\begin{array}{l}\text { Trough- } \\
\text { to- } \\
\text { Trough }\end{array}$ & 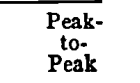 \\
\hline $\begin{array}{l}\text { Annual and semiannual } \\
\text { data }\end{array}$ & & $\begin{array}{r}\text { I879-1907 } \\
\text { (8 pairs) }\end{array}$ & & $\begin{array}{l}\text { r882-r } 908 \\
\text { (7 pairs) }\end{array}$ \\
\hline $\begin{array}{l}\text { Reference cycles } \\
\text { in clearings-debits } \\
\text { Specific cycles in }\end{array}$ & ts .36 & .64 & .43 & .68 \\
\hline Moore index & .76 & .85 & .76 & .79 \\
\hline Monthly data & & $\begin{array}{r}\text { r9o7-r } 960 \\
\text { (10 pairs) }\end{array}$ & & $\begin{array}{l}\text { rgo8-r } 960 \\
\text { (10 pairs) }\end{array}$ \\
\hline $\begin{array}{l}\text { Reference cycles } \\
\text { in clearings-debits } \\
\text { Specific cycles in }\end{array}$ & ts .30 & .54 & .37 & .57 \\
\hline Moore index & .82 & .58 & .75 & $.8 \mathrm{I}$ \\
\hline Whole-period data & & $\begin{array}{r}\text { 1879-196I } \\
\text { (18 pairs) }\end{array}$ & & $\begin{array}{l}\text { 1882-1960 } \\
\text { (1 } 7 \text { pairs) }\end{array}$ \\
\hline $\begin{array}{l}\text { Reference cycles } \\
\text { in clearings-debits } \\
\text { Specific cycles in }\end{array}$ & its .27 & .64 & $.4 \mathrm{I}$ & .62 \\
\hline Moore index & .77 & .70 & .78 & .77 \\
\hline
\end{tabular}

Note: In our full study we have used three measures of the amplitude of the change in money, each both in total and as a rate per month, measuring the change in cycle relatives between reference dates, between step dates, and between specific cycle peaks and troughs in the rate of change. To simplify our presentation here, we restrict the comparison to the total change in amplitude between peaks and troughs in the rate of change.

War cycles 1914-19 and 1938-45 are omitted because of their special characteristics. The r $945-49$ cycle is omitted because the expansion is skipped by the rate of change series (see Table $r$ ). No tied ranks correction is used in getting correlation coefficients. "Amplitude" of rate of change in money stock is expressed in units of the data as plotted in Chart 3, above. For expansions, it is the change in stages $\mathrm{I}-\mathrm{V}$ of the specific cycle; for contractions, the change in stages V-IX of the specific cycle. For clearings-debits the reference cycle amplitude (stages I-V-IX), expressed in reference-cycle relatives, was used. For the Moore index, specific cycle amplitudes only are avail able, but they have a one-to-one correspondence with reference cycles. For full cycles, trough-to-trough, the change from $V$ to IX was sub tracted from the change from I to $V$ to obtain the total rise and fall used in the correlations; for full cycles, peak-to-peak, the change from $I$ to $V$ was subtracted from the change from $V$ to IX.

Source: Rate of change in money stock: Figures underlying Chart 3 were analyzed for specific cycles, as in Burns and Mitchell Measuring Business Cycles, pp. 115-14I; matching of peaks and troughs with reference turns follows Table $I$.

Clearings-debits: Bank clearings outside New York City, monthly, 1879-1919; bank debits outside New York City, monthly, rorg-6r. 1 879-1942: Seasonally adjusted from Historical Statistics of the United States, 1780-1945, Bureau of the Census, 1949, pp. 324-325, 337-388. 1943-6r: Board of Governors of the Federal Reserve System, Division of Bank Operations, mimeographed table, "Bank Debits and Rates of Turnover" (C. 5, Revised Series, 1943-52). December 23. 1953; thereafter Federal Reserve Bulletin, adjusted for seasonal variation by NBER. Reference cycle analysis follows Burns and Mitchell, op. cit., pp. 160-170.

Moore index: Unpublished memorandum by Geoffrey $H$. Moore extending table in ibid., p. 403 , and revising and updating table in Business Cycle Indicators, G. H. Moore, ed., Vol. I, p. 104. An average of three trend adjusted indexes of business activity - A. T. \& T., Persons-Barrons, and Ayres - each of which was analyzed for specific cycles, suppressing specific cycle turns not corresponding to reference cycle turns.

the severity of cyclical movements in general business, even though the timing of the changes in the rate of change in the money stock is not.
2. One way in which we have investigated this relation further is to correlate the ranking of the amplitudes of cyclical movements in the rate of change with the ranking of the amplitudes of the corresponding cyclical movements in general business, as measured by two different indicators: one, bank clearings to rg r9 and bank debits thereafter; the other, an index computed by Geoffrey H. Moore. The correlations, summarized in Table 3 , are throughout positive - for expansions alone, for contractions alone, and for full cycles, for the period before 1908 and for the period since, as well as for the whole period.

The correlations between the rate of change measure and the Moore index are sufficiently high so that, even with the small number of observations on which they are based, they could hardly have arisen from chance. There is a less close connection between the clearings-debits figures and the rate of change, especially in expansions. The Moore index is adjusted for trend and reflects primarily changes in physical units. Likewise, the shift from the total stock of money to the rate of change is, as noted earlier, equivalent to adjusting for trend; in addition, it involves a change from a measure expressed in nominal units - dollars - to a measure expressed in relative units - per cent - and as a flow - per month. The amplitude of clearings-debits, however, is not adjusted for intracycle trend, and clearingsdebits are, in their original form, in dollars. It would be interesting to know whether the adjustment for trend, or the different weight given to financial and physical transactions, is primarily responsible for the closer connection of the Moore index than of clearings-debits to the rate of change.

The table as a whole leaves little doubt that there is a fairly close connection between the magnitude of monetary changes during the course of cycles, and the magnitude of the associated cyclical movement in business. The relation is by no means perfect for the measures we use. But we have no way of knowing from this evidence alone to what extent the discrepancies reflect the inadequacies of our indexes of economic change, the statistical errors in our money series, or a basic lack of con- 
nection between monetary and economic changes.

3. To get further evidence, we have investigated this relation in a different way using annual data. For the period from i 869 to 1960 , we have annual estimates of net national product, and also, of course, annual estimates of the stock of money. For this period, we have computed logarithmic first differences (i.e., yearto-year percentage changes) of both series. We have then computed moving standard deviations (comparable to moving averages) from these rates of change involving $3,4,5$, and 6 terms. To illustrate: for the 3 -term moving standard deviation, we took the initial three rates of change (1869-70, $1870-71,1871-72$ ), computed their standard deviation by the usual statistical formula, ${ }^{7}$ and dated the result as of I 870-7I; then dropped the initial year and added a year, computed the standard deviation for the resulting triplet of rates of change (1870-7I, $1871-72,1872-73$ ), and dated the results as of $187 \mathrm{I}-72$; and so on.

These moving standard deviations are a measure of the variability of the rates of change in the one case, of money; in the other case, of income. If such a computation were made for a strictly periodic series, say, a sine wave of fixed period and fixed amplitude, and if the length of the moving standard deviation were the same as the period of the sine wave (or an integral multiple of it), then the computed moving standard deviation would be constant over time, and its value would be equal to

$\sqrt{I / 2}$ times the amplitude of the sine wave. ${ }^{8}$ If the length of the moving standard deviation were shorter than the period of the sine wave, the computed moving standard deviation would fluctuate over time, its value never exceeding the value just cited. The same proposition holds if the length of the moving standard deviation is longer than the period of the sine wave but not an integral multiple of it, though it is perhaps

${ }^{7}$ That is, estimate of s. d. $=\sqrt{\frac{\Sigma(x-\bar{x})^{2}}{n-1}}$, where $x$ is the observation, $\bar{x}$, the mean, and $n$ the number of items in the group, in this example, 3 .

${ }^{8}$ Let the sine wave be $A \sin \frac{2 \pi}{m} t$, where $t$ is time. Then $m$ is the period of the wave and $A$ the amplitude, the wave fluctuating from $+A$ to $-A$. obvious that, as the moving standard deviation is lengthened, the standard deviation will approach the constant value noted above, since the fractional cycle becomes less and less important compared to the whole cycles included in the computation of the standard deviation.

It follows from these considerations that, for our purpose, which is to see how the amplitude of the cycles in the rate of change in the money stock is related to the amplitude of business cycles, we want to use a number of terms equal to the length of the cycle in which we are interested. This explains why we have used $3,4,5$, and 6 terms, for the reference cycle since 1867 has averaged four years in length but has occasionally been shorter or longer. As it happens, the results are not very different for different numbers of terms, so we present a chart for only the 4-term results, though we give some numerical data for all.

One more point before turning to the results. Net national product, which we are using as an index of general business and whose fluctuations we are interpreting as a measure of the amplitude of business cycles, has a sharp upward trend, though a less steep one than the money stock has, so that it typically declines absolutely during contractions. If we were to take a moving standard deviation of its absolute values, or their logarithms, the result would overestimate cyclical variability because of the intracycle trend, and the overestimate would vary over time as the intracycle trend did. Accordingly, to eliminate the effect of the intracycle trend from our measure of variability, we have used logarithmic first differences for net national product as well. This procedure is of the same class and for the same purpose as the National Bureau's standard technique of estimating full cycle amplitudes by subtracting the change during contraction from the change during expansion. However, the use of first differences can also be taken to mean that what we are calling the amplitude of business cycles refers to a construct rather different from the National Bureau's standard reference cycle; it refers to a cycle in the rate of change in aggregates rather than in the level of aggregates. As is well known, for a sine wave, the rate of change series has the same amplitude and pattern as the original series but 
Chart 5. - Moving Standard Deviation of Annual Rates of Change in Money, i869-1958, and in Income, I871-1958, 4-TERM SERIES

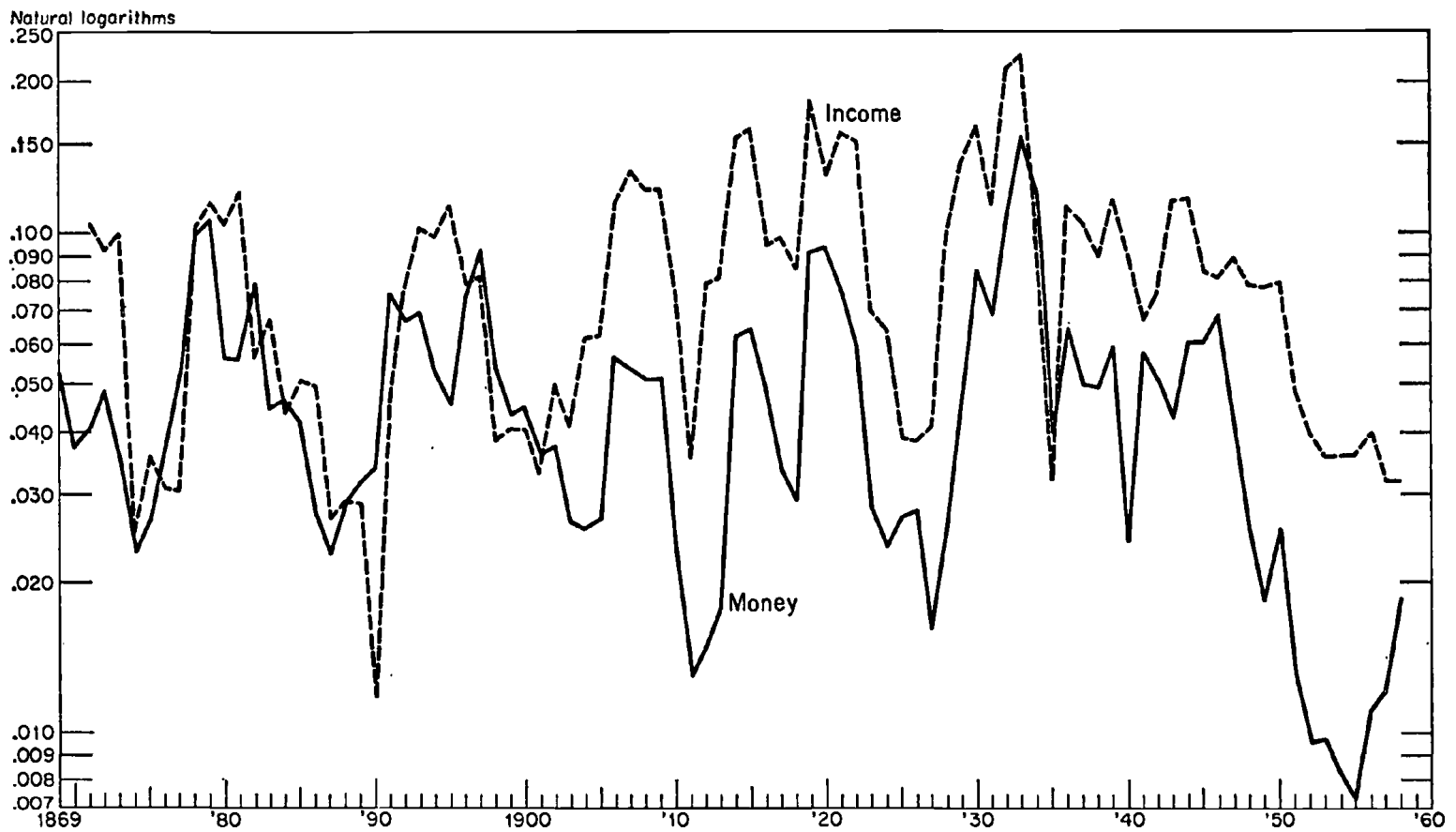

Source: Money figures, described in source for Chart $x$, are annual averages centered on June 30 . Income figures are annual estimates of net national product, beginning 1869 , from worksheets underlying Simon Kuznets, Capital in the American Economy: Its Formation and
Financing, Princeton for NBER, 1961 . For computation of moving standard deviation, see subsection 3 of this section, and footnote 7 .

differs in phase, its peaks and troughs coming one-quarter of a cycle earlier or three-quarters of a cycle later than the peaks and troughs of the original series.

Aside from removing the effect of intracycle trend, another advantage of using the first differences of net national product is that the results would be almost identical for total net national product and net national product per capita. Since population has grown at a steady rate over periods of 3 to 6 years, the use of per capita data would affect only the moving average of the rates of change but not the moving standard deviation.

Chart 5 plots the 4 -term moving standard deviations for money and net national product. It should be noted that since we have used natural logarithms, the vertical scale can be interpreted directly in terms of percentage points. For example, a value of .100 means that the standard deviation is equal to an annual rate of growth of Io percentage points. ${ }^{9}$

${ }^{8}$ Let $\rho(t)$ be the continuous rate of growth from year $t$ to year $t+\mathrm{r}$, so that

$$
X_{t+1}=X_{t} e^{\rho(t)},
$$

The scale on the chart is logarithmic. The reason is that, since the standard error of the estimated standard deviation is proportional to the (true) standard deviation, the standard error of the logarithm of the standard deviation is roughly a constant, regardless of the size of the (true) standard deviation. Hence the logarithmic scale makes sampling fluctuations appear the same size throughout.

It is clear from the chart that there is a close relation between the variability of money and of net national product: the two curves parallel one another with a high degree of fidelity, especially when it is borne in mind that standard deviations based on only four observations (three degrees of freedom) are

where $X_{t}$ and $X_{t+1}$ are successive annual observations. Then $\log _{e} X_{t+1}-\log _{0} X_{t}=\rho(t)$.

Note also that

$$
\log _{e} X_{t+1}-\log _{0} X_{t}=\log _{0}\left(\mathrm{I}+\frac{X_{t+1}-X_{t}}{X_{t}}\right) .
$$

But $\log _{\odot}(\mathrm{r}+k)$ is approximately equal to $k$ for small $k$. Hence the first difference is approximately equal to

$$
\frac{X_{t+1}-X_{t}}{X_{t}} \text {. }
$$


subject to a good deal of sampling variation, ${ }^{10}$ that the net national product and money series are, so far as we know, wholly independent in their statistical construction, and that both are subject to an appreciable margin of error.

At first glance, it appears from Chart 5 that income has become more variable relative to money over the period covered. Unless we are mistaken, this is a statistical artifact. A closer look at the chart will show that the change comes shortly after the turn of the century. Before I900, the standard deviations for money and for net national product are roughly equal in magnitude; subsequent to that date, the standard deviations for net national product are noticeably higher than for money. The reason, we conjecture, is the changing statistical character of the net national product estimates, in particular, the role played in them by interpolation between decennial census years. The effect of interpolation is to smooth greatly the year-to-year changes and so to reduce the estimated standard deviations. For the estimates before 1889 , interpolation played a major role; for those from I9I9 on, a much smaller role. ${ }^{11}$ For the intermediate decades, the role of interpolation relative to independent data for individual years became successively smaller. We cannot find any clear indication in the description of the statistical series that there was a sharp break around $I 900$ in the role of interpolation. However, the data behave as if there were such a break. For the period before 1900 , we conjecture that the standard deviations appreciably understate the variability of income. For the subsequent period, it is much harder to make a comparable judgment. The statistical errors of estimation tend to raise the computed standard deviation; interpolation tends to lower it.

For money, the degree of interpolation in the annual estimates is small throughout (interpolation plays a much larger role in our

\footnotetext{
${ }^{10} \mathrm{~A}$ more precise statement for these data is hard to arrive at, since successive first differences are not statistically independent.

${ }^{11}$ See Simon Kuznets, National Product Since 1869, New York, NBER, r946, pp. $90 \mathrm{ff}$. These considerations have the obvious implication that net national product estimates are untrustworthy as a source of evidence on secular changes in the amplitude of business cycles.
}

monthly estimates). Hence the standard deviations for money are probably overestimates of the "true" standard deviations, thanks to the errors of estimation. However, because of the character of the basic data, such errors are probably appreciably smaller than for net national product.

Aside from the shift in the level of the standard deviations for net national product, the most striking feature of the chart is what appear to be fairly regular cyclical fluctuations, of about 8 to 15 years in length, in the standard deviations of both money and net national product; these are the counterparts of the long swings that have received much attention. However, a warning is in order about any such interpretation of these results. The moving standard deviations for successive years are highly correlated because they have three out of four items in common. As is well known, a moving average applied to a series of random terms will produce a series that seems to move systematically; and the moving standard deviation is a moving average and so has the same effect. For our purposes, what is important is the parallelism of the two series plotted in Chart 5, not the character of their common fluctuations.

Table 4 presents numerical evidence for all four lengths of moving standard deviations we have computed. Because of the break in the net national product data, the results are given separately for the period before and after I899. We used I899 as the dividing point because it is a census year. The results for the separate periods are more meaningful than the results for the period as a whole.

This table reinforces the visual evidence of Chart 5 and adds to it a number of important points. One is that the correlation is generally highest when the standard deviations are compared synchronously; it is generally lowered if standard deviations for money are compared with either later or earlier standard deviations for NNP though, for the earlier period, the correlation is highest when money leads one year for three of the four lengths of moving standard deviations. If there be any lead or lag for the later period, it is presumably less than a year in length. The slightly higher correlations for the later period for NNP leading 
Table 4. - Moving Standard Deviations of Annual Rates of Change in Money and Net National Product: Means, Standard Deviations, and Correlation Coefficients for Different Numbers of Terms

\begin{tabular}{|c|c|c|c|c|c|c|c|c|c|c|c|c|}
\hline \multirow[b]{3}{*}{ Period } & \multirow{3}{*}{$\begin{array}{c}\text { Number of } \\
\text { Terms in } \\
\text { Moving } \\
\text { Standard } \\
\text { Deviations }\end{array}$} & & & & & \multicolumn{7}{|c|}{$\begin{array}{l}\text { CORRELATION COEFFICIENT BETWEEN STANDARD } \\
\text { DEVIATIONS OF MONEY AND NNP }\end{array}$} \\
\hline & & \multicolumn{2}{|c|}{$\begin{array}{l}\text { Mean Standard } \\
\text { Deviation } \\
\text { (natural }\end{array}$} & \multicolumn{2}{|c|}{$\begin{array}{l}\text { Standard Deviation of } \\
\text { Standard Deviation } \\
\text { logarithms) }\end{array}$} & \multicolumn{3}{|c|}{$\begin{array}{c}\text { Money Leading NNP by: } \\
\text { (years) }\end{array}$} & \multirow{2}{*}{$\begin{array}{c}\text { Synchro- } \\
\text { nous }\end{array}$} & \multicolumn{3}{|c|}{$\begin{array}{l}\text { NNP Leading Money by: } \\
\text { (years) }\end{array}$} \\
\hline & & $\mathbf{M}$ & NNP & $\mathrm{M}$ & NNP & 3 & 2 & $I$ & & $\mathbf{I}$ & 2 & 3 \\
\hline \multirow[t]{4}{*}{$1869-1898$} & 3 & .049 & .065 & .022 & .039 & .293 & .535 & .616 & .476 &. $\mathrm{II} 4$ & $-.01 \mathrm{I}$ & -.099 \\
\hline & 4 & .052 & .067 & .023 & .033 & .364 & .648 & .718 & .540 & .263 & -.049 &.$- \mathrm{I} 6_{3}$ \\
\hline & 5 & .054 & .068 & .022 & .029 & .378 & .672 & .717 & .657 & .431 & .044 & -.252 \\
\hline & 6 & .057 & .069 & $.02 \mathrm{I}$ & .027 & .398 & .583 & .755 & .759 & .543 &. $\mathrm{I} 44$ & -.069 \\
\hline \multirow[t]{4}{*}{$1899-1960$} & 3 & .039 & $.08 \mathrm{r}$ & .028 & .048 & .003 &.$I_{3}$ & .345 & .670 & .589 & .248 & .036 \\
\hline & 4 & .044 & .089 & .029 & .046 & .135 & .243 & .456 & $.8 \mathrm{I} 4$ & .721 & .472 & .263 \\
\hline & 5 & .048 & .095 & .029 & .046 & .216 & .385 & .608 & .840 & $.82 \mathrm{I}$ & .637 & .435 \\
\hline & 6 & $.05 \mathrm{I}$ & .100 & .029 & .044 & .272 & $.48 \mathrm{I}$ & .672 & .870 & $.84 \mathrm{I}$ & .707 & .518 \\
\hline \multirow[t]{4}{*}{$1869-1960$} & 3 & .042 & .076 & .027 & .046 & .001 &.$I_{4} I$ & .349 & $.59 \mathrm{I}$ & .429 & .149 & -.026 \\
\hline & 4 & .047 & $.08 \mathrm{I}$ & .027 & .044 & III & .242 & .425 & .687 & $.56 \mathrm{I}$ & $.3 I I$ &. $\mathbf{I 3 3}$ \\
\hline & 5 & .050 & .085 & .027 & .043 & .172 & .348 & .534 & .721 & .665 & .465 & .266 \\
\hline & 6 & .053 & .089 & .027 & .042 & .220 & .404 & .581 & .748 & .690 & .536 & .360 \\
\hline
\end{tabular}

Source: Same as for Chart 5.

by a year than for money leading by a year may reflect a lead of NNP by a fraction of a year. A second point added by the table is that the standard deviation for net national product for the period after 1899 is roughly double the standard deviation for money. ${ }^{12}$ As a first approximation, therefore, the amplitude of cyclical fluctuations in income is twice that in money.

The correlations rise steadily as the number of terms in the moving standard deviations is increased. The rise presumably reflects the smoothing of the standard deviations introduced by the larger number of degrees of freedom and hence the reduction in the role of chance fluctuations. Calculations not summarized in the table indicate that the peak synchronous correlation is reached for seven terms. The fact that the mean standard deviations rise is less easily explained, since these should average the largest for a period equal to the average length of a cycle. The

\footnotetext{
12 The same reason that recommends a logarithmic scale for Chart 5 also suggests an advantage in making computations like those in Table 4 from the logarithms of the moving standard deviations. We have done so for the period from 1899 through 1960 . The correlation results are quite similar. The synchronous results are $.600, .797, .837$, and .880 for $3,4,5$, and 6 periods respectively.

The ratio of the geometric mean of the standard deviation of NNP to the geometric mean of the standard deviation of money is $2.3 \mathrm{I}, 2.25,2.19,2.13$, for $3,4,5$, and 6 periods respectively. This method of estimation therefore suggests that income is roughly $2 \frac{1}{4}$ times as variable as money.
}

explanation is presumably the existence of the longer waves. We conjecture that the mean standard deviation would continue to rise as terms are added and reach a maximum at something like ro to 5 terms.

To summarize these results: They strongly reinforce the evidence from the earlier comparison of reference cycle amplitudes. There is unquestionably a close relation between the variability of the stock of money and the variability of income. This relation has persisted over some nine decades and appears no different at the end of that period than at the beginning, if allowance is made for the changing characteristics of the statistical raw materials.

\section{Cyclical behavior of velocity.}

I. The ratio of income to the stock of money, which is to say, the income velocity of money, has been rising in the post-World War II period. However, over the whole of the more than nine decades our data cover, it has declined sharply, from 4.6 at the outset of the period to $I .7$ at the end. As a result, velocity has frequently declined during both expansions and contractions in general business. When that has not been the case, velocity has conformed positively to the cycle, rising during expansions and falling during contractions. When it has been, the cyclical effect has shown up in a slower rate of decline in expansion than in contraction. The average cyclical patterns 
of velocity, for mild depression and deep depression cycles (excluding war cycles), are given in Chart 6.

Chart 6. - Income Velocity: Average Reference Cycle Patterns for Mild and Deep Depression CyCles, I 870-I958

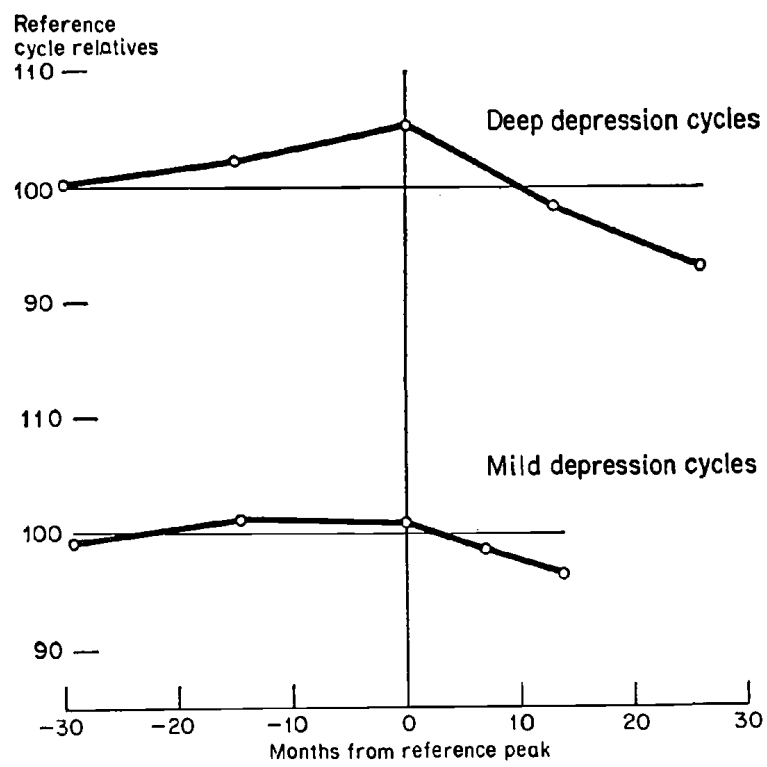

Note: War cycles, not shown, are $1914-19$ and 1938-46. Deep depression cycles are: 1870-78, 1891-1904, 1904-08, 1919-21, 1927-32 and $1932-38$. All others are mild depression cycles. These dates differ from those shown in Charts 2 and 4 , because they are annual instead of monthly.

2. In an earlier article, ${ }^{13}$ it was demonstrated that this cyclical pattern of velocity could be largely though not wholly accounted for by supposing that the amount of money demanded in real terms is linked, not to current measured income and current measured prices, but to longer-term concepts of permanent income and permanent prices. By this interpretation, the amount of money demanded rises during the expansion phase of a cycle in greater proportion than permanent income, as suggested by the secular results. However, measured income rises in still greater proportion, so that measured income rises relative to the stock of money, and conversely during a contraction. While this interpretation does not rule out the possibility that changing interest rates over the cycle play a role in the cyclical behavior of velocity, it assigns them a less im-

${ }^{13}$ Friedman, The Demand for Money: Some Theoretical and Empirical Results, New York, NBER, 1959, Occasional Paper 68, reprinted from Journal of Political Economy, August 1959, pp. 327-351. portant role than it assigns to the discrepancy between measured and permanent concepts.

3. This interpretation has been criticized as assigning much too small a role to interest rates. Henry A. Latané, in particular, has argued that the whole of the movement of velocity, both over longer periods and over the cycle, can be accounted for by changes in interest rates, higher interest rates leading to economy in the use of money and so to higher velocities, and conversely. ${ }^{14} \mathrm{His}$ analysis covers a shorter period than ours does (I909-58).

4. There is no necessary contradiction between these two interpretations, the appearance of contradiction arising primarily from our definition of money as the sum of currency plus all adjusted deposits in commercial banks, and Latané's definition of money as the sum of currency plus adjusted demand deposits alone.

a. Time deposits in commercial banks appear to have a substantially higher income elasticity of demand than currency or demand deposits have, so that the income elasticity of money by our use of the term is doubtless higher than it is by Latane's use of the term. This can explain why we find it necessary to introduce an income effect to explain the secular decline in velocity, while he does not. To put this point differently, we find that the elasticity of demand for (real) money balances with respect to permanent income is about $I .8$ when money is defined as we define it. This is consistent with a corresponding elasticity not much different from unity for Latané's narrower definition, provided the elasticity for time deposits is between 2.5 and $3.5 .{ }^{15}$ Furthermore, since there is a considerable trend element in the movement of interest rates over the period Latané's analysis covers - as, of course, there

\footnotetext{
14 "Cash Balances and the Interest Rate - A Pragmatic Approach," Review of Economics and Statistics, Nov. 1954, pp. 456-460; also idem, "Income Velocity and Interest Rates - A Pragmatic Approach," Employment, Growth, and Price Levels, Joint Economic Committee, Hearings, part 10, 86th Cong., Ist sess., pp. 3435-3443 (reprinted with minor changes in Review of Economics and Statistics, Nov. I 960, pp. 445-449) ; and see Allan H. Meltzer, "The Demand for Money: The Evidence from the Time Series," presented at the Dec. I96I meeting of the Econometric Society.

${ }^{15}$ The elasticity of a total is a weighted average of the elasticities of the components, the weights being the ratio of each component to the total. Over the period from IgI4 to 1960 , commercial bank time deposits have varied from 19 to 44 per cent of money as we define it.
} 
is in income for a much longer period - any excess of the "correct" elasticity over unity could readily be confounded in the statistical analysis with the effects of interest rates. Our own readiness to attribute the decline in velocity to income, despite the strong trend in income, derives primarily from the consistency of such an interpretation with a wide range of other evidence, in particular, cross-section evidence for different states in the United States and for different countries.

b. It is plausible that the division of currency plus deposits between currency plus demand deposits, on the one hand, and time deposits, on the other, is sensitive to rates of interest, since the differential between interest paid on time deposits and interest paid on demand deposits (which can be and for long periods has been negative) and on currency (typically zero) can be expected to widen as interest rates rise - and conversely. Hence a rise in interest rates might be expected to lead to an increase in commercial bank "time deposits relative to commercial bank demand deposits plus currency - and conversely. It follows that the interest elasticity of demand can be expected to be greater in absolute value for currency plus demand deposits, than for currency plus demand deposits plus time deposits in commercial banks.

c. The two preceding points have especial importance for the longer-term movements in velocity. For the cyclical behavior of velocity, the distinction between measured and permanent income can be combined with either demand function, and will help to explain the cyclical behavior of velocity.

Needless to say, neither definition of money can be said to be "the" correct definition. Just where the line is drawn between those temporary abodes of purchasing power we choose to term money and those we term "nearmonies," or "liquid assets," or what not, is largely arbitrary. We have found it convenient to draw the line where we do largely because that enables us to use a single concept for the whole of our period, since the distinction between commercial bank demand and time deposits did not acquire its current significance - or indeed have much significance at all until after r9r4. In the course of using it, we have found it to have some other advantages. ${ }^{16}$ In addition, even for the period since I9I4, it is by no means clear that demand deposits as recorded correspond fully with the economic construct Latané wishes to measure, namely, deposits subject to check. The lower reserves required against time deposits have given banks an incentive to classify as large a fraction of deposits as time deposits as possible. There is some evidence that, particularly during the r920's, banks managed so to classify some deposits that were in effect demand deposits. A full understanding of the behavior of money in business cycles requires an analysis of the components of the money stock, however defined, and of near-monies as well, so, despite our reservations about the meaning of some of his data, we welcome Latané's analysis as a valuable complement to ours.

5. A basically more important question is the extent to which velocity can be regarded as passively reflecting independent changes in its numerator and denominator. This is the presumption implicit in the cycle theories, popular these past few decades, that have regarded investment as the dominant cycle-producing factor. These theories implicitly take for granted that an expansion of investment will produce an expansion in income regardless of what happens to the money stock. In their most extreme form, these theories imply that the magnitude of the expansion in income is independent of the size of any concurrent change in the money stock. If the money stock

\footnotetext{
${ }^{10}$ Still another bit of evidence on which of the two definitions of money is to be preferred is available. We computed correlations like those in Table 4 for the period rgr5-60 between the variability of the narrower definition and the variability of net national product, and also between the variability of our broader definition and the variability of net national product. The broader definition has almost always a somewhat higher correlation coefficient. The synchronous results for standard deviations of varying terms are shown in the following tabulation, giving correlation coefficients between synchronous standard deviations of annual rates of change in money - defined narrowly and broadly - and in net national product, for different number of terms. $\begin{array}{llllllll}M_{1} & .592 & .833 & .865 & .909 & .937 & .93 \mathrm{I} & .9 \mathrm{I2}\end{array}$ $\begin{array}{llllllll}M_{2} & .596 & .785 & .842 & .883 & .907 & .899 & .874\end{array}$ $M_{1}=$ Currency held by the public, plus demand deposits adjusted, plus commercial bank time deposits.
$M_{2}=$ Currency held by the public, plus demand deposits adjusted.

Definition
of Money 3-Term 4-Term 5-Term 6-Term 7-Term 8-Term 9-Term
} 
does not rise, then velocity will simply rise to fill the gap; if the money stock does rise, velocity will not rise as much or may even fall. The most rigorous explicit theoretical formulation of this position is in terms of either a "liquidity trap" - an infinitely elastic liquidity preference function at a finite interest rate - or a completely inelastic demand schedule for investment - a zero response of spending to a change in the rate of interest. Though few economists would explicitly maintain that either the one or the other prevails currently, or has prevailed during most of our past history, many would accept the logically equivalent assertions that the rate of cyclical expansion or contraction can be regarded as fairly rigidly determined by the rise or fall in investment or autonomous expenditure, that the link is far more crucial than any link with the contemporary behavior of the money stock, and can be reversed, if at all, only by a very atypical behavior of the money stock. Some relevant empirical evidence on this issue is summarized in the subsection below on the relative roles of money and investment.

\section{Cyclical behavior of proximate determinants of the money stock.}

r. Changes in the stock of money can, arithmetically, be attributed to changes in three proximate determinants, each under the immediate control of a different class of economic actors:

a. High-powered money, consisting of currency held by the public, plus currency held in bank vaults, plus deposits of banks at Federal Reserve Banks. This total is either a consequence of international payment flows and associated gold movements, or of Treasury or Federal Reserve policy.

b. The division of the public's money holdings between currency and deposits, which can be summarized by any one of a number of ratios - of currency to the money stock; of currency to deposits; or of deposits to currency. This division is in the first instance determined by the public, the holders of money, though, of course, the public's decision is affected by the terms offered by banks for deposits.

c. The relation between deposits and the amount of high-powered money held by banks, which can be termed their reserves. This relation can be summarized by either the ratio of reserves to deposits or its reciprocal, the ratio of deposits to reserves. This ratio is in the first instance determined by banks though, of course, their decision is affected by legal requirements imposed by the government, by the terms they must offer to obtain deposits, and by the returns they can receive on the alternative assets they acquire.

Given the two ratios, a rise in high-powered money implies a proportional rise in the stock of money. Given the amount of high-powered money and the deposit-reserve ratio, a rise in the deposit-currency ratio implies a rise in the stock of money, because it means that less high-powered money is required to meet the currency demands of the public and more is available for bank reserves to be multiplied by the deposit-reserve ratio. Similarly, given the amount of high-powered money and the deposit-currency ratio, a rise in the depositreserve ratio implies a rise in the stock of money, because it means that each dollar of high-powered money held by banks gives rise to a larger number of dollars of deposits.

2. Phillip Cagan has analyzed in detail the contribution of changes in each of these three proximate determinants to the cyclical fluctuations in the rate of change in the money stock. ${ }^{17} \mathrm{He}$ finds that the deposit-currency ratio was the most important single contributor. Throughout the period from $\mathrm{r} 877$ to 1954 , it accounted on the average for roughly half the cyclical fluctuations in the rate of change in the money stock. Though this fraction varied from cycle to cycle, it did not change in any consistent secular fashion and was not markedly different for severe and mild movements. The main deviation in its contribution occurred at times of money panics in which it often played a dominant role.

Changes in high-powered money were as large in amplitude as changes in the depositreserve ratio but much less regular in timing. Changes in the deposit-reserve ratio were reg-

\footnotetext{
${ }^{17}$ See his forthcoming monograph, "Determinants and Effects of Changes in the U.S. Money Stock, I875-1955," a National Bureau study.
} 
ular in timing but relatively small in amplitude.

3. Cagan finds that the main impact of the Federal Reserve System has been on the relative importance of changes in high-powered money and in the deposit-reserve ratio. By providing banks with an alternative source of liquidity, the Reserve System intensified a tendency for banks to trim any excess of reserves over legal requirements - a tendency fostered in earlier decades by the Treasury's assumption of enlarged money market responsibilities. The result was a reduction in the amplitude of cyclical movements in the reserve ratio after I9I4. However, this was more than offset by an increase in the amplitude of cyclical movements in high-powered money.

4. The deposit-currency ratio had a rising long-term trend to 1929 , declined substantially thereafter until the end of World War II, and has since been rising. Relative to these longerterm movements, the deposit-currency ratio tended to rise during the early part of expansions, at first at an increasing rate; to reach a peak near mid-expansion; then to decline to mid-contraction; and then to start rising. Cagan shows that these movements played an important part in accounting for the tendency of the rate of change in the money stock to reach its peak around mid-expansion and its trough around mid-contraction. He attributes the timing of movements in the deposit-currency ratio to divergent cyclical patterns in the velocity of currency and deposits.

5. The deposit-reserve ratio rose during most of the period covered, except for its sharp decline during the later 1930's. Relative to trend, it tended to rise during expansions, reaching its peak before the reference peak, and tended to decline during contractions, reaching its trough before the reference trough.

6. These patterns bespeak a rather complex feedback mechanism whereby changes in business activity react on the stock of money. This feedback mechanism has not yet been worked out in the detail that would be desirable.

\section{Relative roles of money and investment in the cycle.}

In an extensive statistical study using standard correlation techniques rather than the $\mathrm{Na}$ - tional Bureau's cycle analysis, one of us in collaboration with David Meiselman investigated the relative stability of monetary velocity and the investment multiplier. ${ }^{18}$ Both the stock of money and the level of autonomous expenditures are positively related to consumption and to income over both short and long spans of years. However, it turns out that the correlation is generally much higher for money than for autonomous expenditures. Moreover, the partial correlation between money and consumption, holding autonomous expenditures constant, is roughly the same as the simple correlation, whereas the partial correlation between autonomous expenditures and consumption, holding the stock of money constant, is on the average roughly zero, being sometimes positive, sometimes negative. Similar results were obtained for year-to-year and quarterto-quarter changes in the stock of money, autonomous expenditures, and consumption.

Additional evidence is provided by correlations between the variability of annual changes in money and in consumption, on the one hand, and between the variability of annual changes in investment and in consumption, on the other. Because there are occasional negative figures for net capital formation, we used gross capital formation as the measure of investment and computed first differences of logarithms and moving standard deviations of the first differences, as in Table 4, for money, consumption, and investment. The synchronous correlation coefficients we obtained are consistently higher, both for the period as a whole and for the period since $\mathrm{r} 899$, for moneyconsumption variability than they are for investment-consumption variability. These are exactly the same results as in the Friedman and Meiselman study, although derived by a wholly different procedure. For the full period, the correlation coefficient for money-investment variability is slightly lower than for investment-consumption variability; for the period since 1899 , slightly higher. In addition, the partial correlation between money-consumption variability, holding investment vari-

${ }^{18}$ Milton Friedman and David Meiselman, "The Relative Stability of Monetary Velocity and the Investment Multiplier in the United States, 1897-1958," in Stabilization Policies (in press, 1963), pp. 165-268, Prentice-Hall for the Commission on Money and Credit. 
ability constant, is significantly higher than the partial correlation between investmentconsumption variability, holding money variability constant; for the period since 1899 , the partial correlation between money-investment variability, holding consumption constant, is significantly higher than the partial correlation between investment-consumption variability, holding money constant, although for the whole period, the former is lower. Essentially the same results were obtained for the simple and partial correlations with leads and lags. ${ }^{19}$

These results are striking because they contradict so sharply the widespread presumption among economists that investment (or, more generally, autonomous expenditures) is the prime mover in cyclical fluctuations, transmitting its influence to the rest of income via a multiplier effect on consumption. So far as these results go, they suggest that, for a given stock of money, there is no systematic relation at all between autonomous expenditures and consumption - in experience, the multiplier effect on consumption is as likely to be negative as positive. ${ }^{20}$ These results may of course be misleading, because some crucial variables have been neglected, or because the definition used for autonomous expenditures is inappropriate, or for some other reason. But they tend to be supported by preliminary results for other countries, and we know of no con-

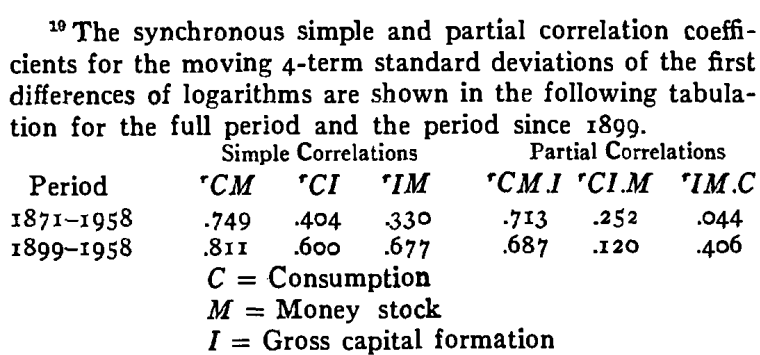

If net capital formation is used as the measure of investment, first differences of absolute values must be obtained. We calculated the standard deviation of those first differences, and the logarithm of the standard deviation, and then correlated the logarithms as above. There is a trend element in these calculations that it would be desirable to eliminate but, even so, the correlation coefficients are similar to those described for the standard deviation of first differences of logarithms.

${ }^{20}$ The investment multiplier is generally defined as the ratio of a change in income rather than in consumption to the change in autonomous expenditures to which the change in income is attributed. In these terms, the conclusion is that the multiplier is as likely in practice to be less than unity as greater than unity. trary evidence for the United States. The widespread presumption to the contrary that unquestionably does exist, whether it be right or wrong, does not rest, so far as we can see, on any coherent, organized body of empirical evidence. $^{21}$

\section{Some Plausible Interpretations of the Factual Evidence}

The stock of money displays a consistent cyclical behavior which is closely related to the cyclical behavior of the economy at large. This much the factual evidence summarized above puts beyond reasonable doubt.

That evidence alone is much less decisive about the direction of influence. Is the cyclical behavior of money primarily a reflection of the cyclical behavior of the economy at large, or does it play an important independent part in accounting for the cyclical behavior of the economy? It might be, so far as we know, that one could marshal a similar body of evidence demonstrating that the production of dressmakers' pins has displayed over the past nine decades a regular cyclical pattern; that the pin pattern reaches a peak well before the reference peak and a trough well before the reference trough; that its amplitude is highly

\footnotetext{
${ }^{21}$ It is well established that ( 1 ) investment expenditures have a wider cyclical amplitude than consumption expenditures have relative to their mean value; (2) orders and other series reflecting investment decisions, as contrasted with expenditures, display a consistent tendency to lead cyclical turns; (3) there is a high correlation between consumption and income.

None of these is very strong evidence for the multiplier effect of investment on consumption, which is the point at issue. Item I simply means that investment is a more variable component of income than consumption is; it says nothing about whether both fluctuate in response to common influences, investment influencing consumption, or consumption influencing investment. Note that a strict multiplier model has no implications about whether autonomous or induced expenditures should show wider absolute fluctuations. Absolute fluctuations in induced expenditures would presumably be wider or narrower as the usual multiplier is greater or less than 2 .

Item 2 has more significance and has some suggestive value. However, it may simply mean that decisions are affected early by whatever also affects spending later on (see page $6 \mathrm{I}$, below). Item 3 is entirely irrelevant. Consumption is a major component of income, as both are measured. For multiplier effects, what is important is the effect of investment on consumption. See M. Friedman and G. S. Becker, "A Statistical Illusion in Judging Keynesian Models," Journal of Political Economy, Feb. 1957, pp. 64-75.
} 
correlated with the amplitude of the movements in general business. It might even be demonstrated that the simple correlation between the production of pins and consumption is higher than the simple correlation between autonomous expenditures and consumption; that the partial correlation between pins and consumption - holding autonomous expenditures constant - is as high as the simple correlation; and that the correlation between consumption and autonomous expenditures holding the production of pins constant - is on the average zero. We do not, of course, know that these statements are valid for pins and, indeed, rather doubt that they are but, even if they were demonstrated beyond a shadow of doubt, they would persuade neither us nor our readers to adopt a pin theory of business cycles.

If the only decisive statistical evidence fo: money were comparable to the items just cited for pins, it would correspondingly not justify the acceptance of a monetary theory of business cycles. At the same time, it is worth noting that, even then, the monetary theory and the pin theory would by no means be on all fours. Most economists would be willing to dismiss out of hand the pin theory even on such evidence; most economists would take seriously the monetary theory even on much less evidence, which is not by any means the same as saying that they would be persuaded by the evidence. Whence the difference? Primarily, the difference is that we have other kinds of evidence. We know that while pins are widely used and occasionally of critical importance, taken as a whole, they are a minor, if not trifling, item in the economy. We expect the effect to be in rough proportion to the cause, though this is by no means always the case - a rock can start a landslide. We can readily conceive of an economy operating without pins yet experiencing cycles like those of history; we can readily conceive of large autonomous changes occurring in the production of pins, but we cannot readily conceive of any channels through which such autonomous changes could have wide-reaching effects on the rest of the economy. Men who have thought about and studied these matters have never been led to suggest the pin industry as a prime mover in the cyclical process. In all these respects, the monetary theory is on a wholly different footing. We know that money is a pervasive element in the economy; that the stock of money is sizable compared with other aggregate economic magnitudes; that fluctuations of the kind we call business cycles have apparently occurred only in an economy in which "economic activities are ... carried on mainly by making and spending money." ${ }^{22}$ We not only can conceive of the money stock's being subject to large autonomous changes, but we can also readily conceive of channels through which such changes could have far-reaching effects on the rest of the economy. Men who have thought about and studied these matters have been led to give money a critical role in their theories.

One more preliminary observation. The key question at issue is not whether the direction of influence is wholly from money to business or wholly from business to money; it is whether the influence running from money to business is significant, in the sense that it can account for a substantial fraction of the fluctuations in economic activity. If the answer is affirmative, then one can speak of a monetary theory of business cycles or - more precisely - of the need to assign money an important role in a full theory of business cycles. The reflex influence of business on money, the existence of which is not in doubt in light of the factual evidence summarized above, would then become part of the partly self-generating mechanism whereby monetary disturbances are transmitted. On the other hand, if the influence from money to business is minor, one could speak of a cyclical theory of monetary fluctuations but not of a monetary theory of business cycles. To illustrate again with pins: Changes in business conditions doubtless affect the production of pins, and no doubt there is some feedback effect of changes in the production of pins on general business. But, whereas the first effect may well be large relative to the total fluctuations in pin production, the feedback effect is almost certainly trivial relative to the fluctuations in business. Hence we are ready to accept a business cycle theory of pin

\footnotetext{
${ }^{22}$ Wesley C. Mitchell, Business Cycles: the Problem and Its Setting, New York, NBER, 1927, Chapter II, and p. 62.
} 
production but not a pin theory of business cycles.

The factual evidence summarized above goes beyond the list of items we conjectured for pins and contains some bits that are relevant to the key question at issue. The most important is the fact that the relation between money and business has remained largely unchanged over a period that has seen substantial changes in the arrangements determining the quantity of money. During part of the period, the United States was on an effective gold standard, during part, on an inconvertible paper standard with floating exchange rates, during part, on a managed paper standard with fixed exchange rates. The commercial banking system changed its role and scope greatly. The government arrangements for monetary control altered, the Federal Reserve System replacing the Treasury as the formal center of control. And the criteria of control adopted by the monetary authorities altered. If the predominant direction of influence had been from business to money, these changes might have been expected to alter the relation between business changes and monetary changes, but the relation has apparently remained much the same in both timing and amplitude. ${ }^{23}$ Yet this evidence is by no means decisive. As noted above, Cagan shows that the public's decisions about the proportion in which it divides its money balances between currency and deposits is an important link in the feedback mechanism whereby changes in business affect the stock of money. The changes in monetary arrangements have affected greatly the trends in the deposit-currency ratio but appear not to have affected its cyclical behavior. Hence this part of the supply mechanism has been roughly constant and has played a roughly constant role over the whole period.

In our view, the most convincing evidence supporting the idea that money plays an important independent part is not the evidence summarized in the first part of this paper but evidence of a rather different kind - that garnered from study of the historical circumstances underlying the changes that occurred

\footnotetext{
${ }^{23}$ See also comments in Friedman, "The Lag in Effect of Monetary Policy," pp. 449-450.
}

in the stock of money. ${ }^{24}$ This evidence is much more clear cut for major movements than for minor.

\section{Major economic fuctuations.}

Major movements in U.S. history include the deep depressions used here to distinguish deep from mild depression cycles in our classification of historical reference cycles (see Chart 2 for the classification); the substantial inflations which have occurred primarily during wartime; and a few long-continued movements in one direction, such as the generally rising level of money income and prices from I 896 to I9I3. With respect to these events, the historical record justifies two important generalizations.

I. There is a one-to-one relation between monetary changes and changes in money income and prices. Changes in money income and prices have, in every case, been accompanied by a change in the rate of growth of the money stock, in the same direction and of appreciable magnitude, and there are no comparable disturbances in the rate of growth of the money stock unaccompanied by changes in money income and prices.

2. The changes in the stock of money cannot consistently be explained by the contemporary changes in money income and prices. The changes in the stock of money can generally be attributed to specific historical circumstances that are not in turn attributable to contemporary changes in money income and prices. Hence, if the consistent relation between money and income is not pure coincidence, it must reflect an influence running from money to business.

INFLATIONARY EPISODES. The second generalization requires little more than its statement to be recognized as true for the inflationary episodes. During periods of U.S. engagement in wars, the increased rate of growth of the money stock stemmed from use of the printing press, in more or less subtle ways, to help finance government military expenditures. During our neutrality in World War I from I9I4 to early I9I 7 , it had its origin

\footnotetext{
${ }^{24}$ For the United States, since the end of the Civil War, see our forthcoming volume, "A Monetary History of the United States, I867-I960."
} 
in use by the Allies of their gold reserves to finance war purchases here. During those war years, the reflex influence of the rising tide of business on the stock of money was in the opposite direction to the actual movement in the money stock, since business expansion of itself tended to produce a worsening in the balance of payments and hence an outflow of gold or a decreased inflow.

The situation is equally clear from 1896 to I9r3. The rise in the stock of money reflected predominantly an increase in the U.S. gold stock, which was part of a worldwide growth of the gold stock emanating from the discovery of new mines and improvements in techniques of extracting gold from low-grade ore. The domestic expansion alone would have made for gold outflows. The feedback was therefore counter to the main current. ${ }^{25}$

For the wartime episodes, the evidence is equally consistent with a different theory, that the independent force was a major shift in government spending propensities; that the shift in spending propensities would have had the same effect on income and prices if it had been financed wholly by borrowing from the public at large with an unchanged money stock, rather than being financed in part by the use of monetary reserves (as it was in the early years of World War I) or by government creation of money (as in the other war years); that it was not financed wholly by borrowing because resort in part to use of monetary reserves and the printing press was politically easier and perhaps financially cheaper.

Evidence from the study by Friedman and Meiselman (discussed in the subsection on the relative roles of money and investment, page. 47, above) rather decisively contradicts this alternative explanation. In any event, the alternative explanation will not hold for the I896-rgr 3 inflation, since there was no obvious independent shift of major magnitude in spending propensities. The only immediate factor producing such a shift that comes to mind is the income earned from gold production. However, although the increase in the stock of gold over that period was large compared to the

\footnotetext{
${ }^{25}$ This point is discussed in more detail in Cagan's forthcoming "Determinants and Effects of Changes in the U.S. Money Stock, 1875-1955."
}

gold stock at the start and was capable of producing large increases in the stock of money via a multiplicative effect on other kinds of money, the gold stock itself was a small fraction of the total money stock, and the increase in the money stock only a fraction of the increase in money income. Hence, the value of gold production was a small fraction indeed of the increase in income. ${ }^{26}$ The increased gold production could hardly have produced the observed increase of money income through any spending multiplier effect. But any effect it might have had must have been through its effect on the stock of money.

DEEP DEPREsSIons. For deep depressions, the historical evidence justifying our second generalization is as clear as for the inflationary episodes, though less well known and hence less self-evident. A summary statement of the proximate source of the change in the money stock will in most instances enable the reader to judge for himself the extent to which the decline in the stock of money can be explained by the contemporary change in money, income, and prices.

I875-78: Political pressure for resumption led to a decline in high-powered money, and the banking crisis in 1873 and subsequent bank failures to a shift by the public from deposits to currency and to a fall in the depositreserve ratio.

I892-94: Agitation for silver and destabilizing movements in Treasury cash produced fears of imminent abandonment of the gold standard by the United States and thereby an outflow of capital which trenched on gold stocks. Those effects were intensified by the banking panic of I893, which produced a sharp decline, first in the deposit-currency ratio and then in the deposit-reserve ratio.

I907-08: The banking panic of 1907 led to

\footnotetext{
${ }^{28}$ For the United States from 1896 to 1913 , the value of the gold stock increased by roughly $\$ \mathrm{r} .4$ billion or by about $\$ 80$ million a year; net national product increased from about $\$ 11$ billion in 1896 to $\$ 34$ billion in 1913 or at the rate of about $\$ 1,300$ million a year.
} 
a sharp decline in the deposit-currency ratio and a protective attempt by banks to raise their own reserve balances, and so to a subsequent fall in the deposit-reserve ratio.

1920-2r: Sharp rises in Federal Reserve discount rates in January $\mathrm{r} 920$ and again in June r920 produced, with some lag, a sharp contraction in Federal Reserve credit outstanding, and thereby in high-powered money and the money stock.

1929-33: An initial mild decline in the money stock from r929 to r 930 , accompanying a decline in Federal Reserve credit outstanding, was converted into a sharp decline by a wave of bank failures beginning in late r930. Those failures produced (I) widespread attempts by the public to convert deposits into currency and hence a decline in the deposit-currency ratio, and (2) a scramble for liquidity by the banks and hence a decline in the depositreserve ratio. The decline in the money stock was intensified after September I93 I by deflationary actions on the part of the Federal Reserve System, in response to England's departure from gold, which led to still further bank failures and even sharper declines in the deposit ratios. Yet the Federal Reserve at all times had power to prevent the decline in the money stock or to increase it to any desired degree, by providing enough high-powered money to satisfy the banks' desire for liquidity, and almost surely without any serious threat to the gold standard.

I937-38: The doubling of legal reserve requirements in a series of steps, effective in 1936 and early 1937 , accompanied by Treasury sterilization of gold purchases led to a halt in the growth of high-powered money and attempts by banks to restore their reserves in excess of requirements. The decline in the money stock reflected largely the resultant decline in the deposit-reserve ratio.

A shift in the deposit-currency ratio and the accompanying bank crises played an important role in four of these six episodes. This ratio, as we have seen, has a systematic cyclical pattern which can be regarded as a feedback effect of business on money. However, in each of those episodes, the shift in the deposit-currency ratio represented a sharp departure from the typical cyclical response and, in at least two ( $1875-78$ and $1892-94$ ), represented a subsequent reaction to an initial monetary disturbance that had no such close link with contemporary changes in money income and prices. Moreover, in two episodes (1920-2 I and $1937-38$ ), neither a shift in the depositcurrency ratio nor bank failures played any role. And such a shift has played no important role in any of the large expansions in the stock of money. A fractional reserve banking structure susceptible to runs is an institutional feature that renders the stock of money sensitive to autonomous deflationary changes; hence runs may frequently play an important role in sharp declines. This feature, however, is clearly not essential for a large economic change to be accompanied by a large monetary change in the same direction.

The 1907-08 episode is a particularly nice example of the intermixture of autonomous monetary disturbances and a feedback. The failure of the Knickerbocker Trust Company in the fall of 1907 converted what had been a mild decline in the money stock as a result of gold exports and a consequent decline in high-powered money into a severe decline as a result of bank runs and a consequent decline in the deposit-currency ratio. The accompanying sharp rise in short-term interest rates and a premium on currency produced a large gold inflow. The accompanying sharp intensification in the business decline worked in the same direction by its effect on the balance of international payments. Since the runs were prevented from producing widespread bank failures through the concerted suspension by banks of convertibility of deposits into cur- 
rency, these feedback effects fairly promptly reversed the money decline and, along with the reversal, the business decline came to an end.

CONCLUSIONS FOR MAJOR MOVEMENTS. The factors that produced the changes in the stock of money are autonomous only in the sense of not being directly attributable to the contemporary cyclical changes in money income and prices. In a broader context, each of course has its origins and its explanation, and some are connected fairly clearly with longerterm economic developments. There can be no doubt, for example, that the silver agitation was intensified by prior declining agricultural prices, or that the financial boom in the early I900's encouraged financial activities which laid the basis for Knickerbocker Trust's failure, or that the worldwide declining price trend of the I870's and I880's encouraged exploration for gold and improvement of refining techniques.

The narrower sense is, however, important for our purpose. The question at issue is whether the one-to-one relation between monetary change and major economic change can be explained by a relation running from economic change to money, as a one-to-one relation between changes in pin production and in economic activity could be explained if it existed. Such an explanation would require that the changes in money be connected rather rigidly with either the contemporary changes in economic conditions or more basic factors that could account alike for the course of economic events and for the changes in the stock of money. The demonstration that the major changes in the stock of money have been attributable to a variety of sources, many of which are connected directly neither with contemporary business developments nor with earlier business developments - which themselves can be regarded as determining the contemporary course of business - therefore contradicts any such explanation of the oneto-one relation between economic change and monetary change.

There seems, to us, accordingly, to be an extraordinarily strong case for the propositions that (I) appreciable changes in the rate of growth of the stock of money are a necessary and sufficient condition for appreciable changes in the rate of growth of money income; and that (2) this is true both for long secular changes and also for changes over periods roughly the length of business cycles. To go beyond the evidence and discussion thus far presented: our survey of experience leads us to conjecture that the longer-period changes in money income produced by a changed secular rate of growth of the money stock are reflected mainly in different price behavior rather than in different rates of growth of output; whereas the shorter-period changes in the rate of growth of the money stock are capable of exerting a sizable influence on the rate of growth of output as well.

These propositions offer a single, straightforward interpretation of all the historical episodes involving appreciable changes in the rate of monetary growth that we know about in any detail. ${ }^{27}$ We know of no other single suggested interpretation that is at all satisfactory and have been able to construct none for ourselves. The character of the U.S. banking system - in particular, for most of its history, the vulnerability of the system to runs on banks - can come close to explaining why sizable declines in money income, however produced, should generally be accompanied by sizable declines in the stock of money; but this explanation does not hold even for all declines, and it is largely irrelevant for the rises. Autonomous increases in government spending propensities plus the irresistible political attraction of the printing press could come close to providing a single explanation for wartime inflations, accounting for the coin-

\footnotetext{
${ }^{27}$ Though we have summarized here and have, ourselves, investigated in detail only the U.S. experience since 1867 , this statement is deliberately worded so as to cover a wider range of experience. For example, it is consistent with the hyperinflations studied by Cagan ("The Monetary Dynamics of Hyperinflation," Studies in the Quantity Theory of Money, M. Friedman, ed., University of Chicago Press, r956, pp. 25-117); with U.S. experience during the I830's and 1840 's, studied by George Macesich ("Monetary Disturbances in the United States, 1834-45," unpublished Ph.D. thesis, University of Chicago, June I958) ; with U.S. experience during the Revolutionary War, the War of 1812 , and the Civil War; with Chilean experience, as studied by John Deaver "The Chilean Inflation and the Demand for Money," unpublished Ph.D. thesis, University of Chicago, I96I) ; with the price revolution in the sixteenth century, as studied by Earl J. Hamilton (American Treasure and the Price Revolution in Spain, 1501-1650, Harvard University Press, 1934).
} 
cidence of rising incomes and rising stock of money without any necessary influence running from money to income; but this explanation cannot account for peacetime inflations, in which the growth of the money stock has reflected a rise in specie rather than in government-issued money; and it is not even a satisfactory explanation for the wartime episodes, since price rises in different wartime episodes seem more closely related to the concurrent changes in the stock of money than to the changes in government expenditure. ${ }^{28}$

It is perhaps worth emphasizing and repeating that any alternative interpretation must meet two tests: it must explain why the major movements in income occurred when they did, and also it must explain why such major movements should have been uniformly accompanied by corresponding movements in the rate of growth of the money stock. The monetary interpretation explains both at the same time. It leaves open the reasons for the change in the rate of growth of the money stock and, indeed, at this point is highly eclectic, taking account of the fact that historically there have been many different reasons.

We have emphasized the difficulty of meeting the second test. But even the first alone is hard to meet except by an explanation which asserts that different factors may from time to time produce large movements in income, and that these factors may operate through diverse channels - which is essentially to plead utter ignorance. We have cited several times the apparently widespread belief in investment as the prime mover. The alternative explanation for times of war, suggested above, is a special application of this theory, with investment broadened to mean "autonomous expenditures" and government spending included in the same category. But even for the first test alone, we find it hard to accept this theory as a valid general explanation: can a drastic collapse in autonomous investment explain equally I873-79, I892-94, I920-2 I, I929-33, I937-38? Capital formation at the end of the seventies was apparently one and one-half times its level at the beginning and

\footnotetext{
${ }^{29}$ See Friedman, "Price, Income, and Monetary Changes in Three Wartime Periods," American Economic Review, May 1952, pp. 612-625.
}

seems not to have slumped seriously at any time during the decade, judging by the rough indications given by Kuznets' figures. ${ }^{29}$ The I 890's saw some decline, but the following decade was marked by a vigorous and sustained rise. The I920-2 I episode was destined to be followed by a construction and investment boom. If the experience of $1920-2 \mathrm{I}$ is to be interpreted as a result of an investment collapse, that decline must have been a consequence of the decline in government expenditures and the subsequent collapse of inventory speculation before fixed capital expenditures had developed to take their place. But why, then, did the sharp decline in government expenditures after World War II not produce a subsequent economic collapse? Emphasis on inventory speculation involves a highly episodic interpretation, since it characterizes few of the other episodes. Surely, one cannot adduce that in World War I, slow using up of investment opportunities - often implicitly or explicitly called on to explain why, from time to time, there is allegedly a collapse of investment or a position of stagnation - was responsible for the I920-2 I recession. This is an equally implausible explanation for $1937-38$ and, as already implied, for earlier episodes as well.

Of course, in most or all of these contractions, the incentive to invest and the actual amount spent on investment declined. The question at issue, however, is whether the decline was a consequence of the contemporary economic collapse - triggered, we would say, by monetary changes - or the ultimate working out of autonomous elements of weakness in the demand for investment that themselves triggered the contraction.

Even if all these episodes of contraction can somehow be interpreted as reflecting an autonomous decline in investment, is a sharp increase in investment opportunities a satisfactory explanation for the worldwide $1897-19$ I 3 rise in money income? If money is not a critical link but only a passive accompaniment of change, how is it that China escaped the early years of the Great Depression? We would say thanks to being on a silver standard and hence having a floating exchange rate vis-à-vis gold currencies,

\footnotetext{
${ }^{2}$ Kuznets, Capital in the American Economy: Its Formation and Financing, Princeton for NBER, 1961, p. 572.
} 
whereas all countries linked to gold were enmeshed in the depression. And how is it that China had the most severe contraction of all in the years from 1933 to I936, when our silver purchase program drained silver from China and caused a sharp decline in its money stock, whereas the rest of the world was in a period of business expansion? And we could extend this list of embarrassing questions without difficulty.

We feel as if we are belaboring the obvious and we apologize to any reader who shares that feeling. Yet repeated experience has led us to believe that it is necessary to do so in order to make clear how strong is the case for the monetary explanation of major movements in money income.

Of course, it is one thing to assert that monetary changes are the key to major movements in money income; it is quite a different thing to know in any detail what is the mechanism that links monetary change to economic change; how the influence of the one is transmitted to the other; what sectors of the economy will be affected first; what the time pattern of the impacts will be, and so on. We have great confidence in the first assertion. We have little confidence in our knowledge of the transmission mechanism, except in such broad and vague terms as to constitute little more than an impressionistic representation rather than an engineering blueprint. Indeed, this is the challenge our evidence poses: to pin down the transmission mechanism in specific enough detail so that we can hope to make reasonably accurate predictions of the course of a wide variety of economic variables on the basis of information about monetary disturbances. In the section below on the relation between variations in income and money, we outline one part of the transmission mechanism which can account for the greater amplitude of variation in income than in money and on which we have some empirical evidence; in the last section, we sketch in a much more tentative way the major channels through which monetary fluctuations might be able to account for economic fluctuations, both the major movements we have so far been considering, and the minor movements to which we now turn.
Minor economic fluctuations.

The case for a monetary explanation is not nearly so strong for the minor U.S. economic fluctuations that we have classified as mild depression cycles as the case is for the major economic fluctuations. Clearly, the view that monetary change is important does not preclude the existence of other factors that affect the course of business or that account for the quasirhythmical character of business fluctuations. We have no doubt that other factors play a role. Indeed, if the evidence we had were solely for the minor movements, it seems to us most unlikely that we could rule out - or even assign a probability much lower than 50 per cent to the possibility that the close relation between money and business reflected primarily the influence of business on money.

If we are inclined to assign a probability much lower than 50 per cent, it is primarily because the evidence for minor movements does not stand alone. If money plays an independent role in major movements, is it likely to be almost passive in minor movements? The minor movements can be interpreted as less virulent members of the same species as the major movements. Is not a common explanation for both more appealing than separate explanations, especially when there is no well-tested alternative separate explanation?

A fully satisfactory explanation of the minor movements would require an explicit and rigorously stated theory, which could take the form of a series of simultaneous differential equations describing the reaction mechanism of the economy, together with a specification of the joint distribution function of the random disturbances impinging on it, and a specification of the systematic disturbances that could be introduced into it. Our belief that money plays an important role in minor movements is equivalent to asserting that some of these differential equations would contain the stock of money as a variable; that disturbances in the stock of money are among the random or systematic disturbances impinging on the system; and that these disturbances alone would be capable of generating a path for such major economic variables as money income, prices, output, and the like, comparable to the path they actually follow during mild depression cycles. 
One factor that has doubtless contributed to skepticism about a monetary theory is the fact, documented above, that fluctuations in income are wider in relative amplitude than fluctuations in the stock of money. We have seen that income velocity varies positively over the cycle, which means that income varies more widely than money. We have seen also that the standard deviation of year-to-year percentage changes in income tends to be roughly double the standard deviation of year-to-year changes in the stock of money. How is it that such small changes in money can produce so much larger changes in income? Why should marginal velocity be systematically higher than average velocity?

While we are far from having a rigorous and comprehensive theory to answer this and related questions, in the next section we outline one element of such a theory which can, in our view, explain the difference in amplitude; and in pages $59-63$, we outline even more broadly a tentative transmission mechanism.

\section{Relation between amplitude of cyclical varia- tions in income and money.}

One of us has elsewhere suggested that holders of money can be regarded as adjusting the nominal amount they demand to their views of their long-run income status - itself a measure of their wealth - of the long-run level of prices, and of the returns on alternative assets. $^{30}$ Let us neglect for the time being the effect of returns on other assets, as well as still other possible variables, so that we can write the relationship for the community as

$$
M_{d}=P_{p} f\left(y_{p}\right),
$$

where $M_{d}$ is nominal amount of money per capita, $P_{p}$ is permanent prices, and $y_{p}$ is permanent aggregate real income per capita. ${ }^{31}$ The capital letters here and later refer to magnitudes in nominal terms or current prices, the

\footnotetext{
${ }^{30}$ Friedman, The Demand for Money.

${ }^{31}$ We call to the reader's attention the difference in this notation from that in The Demand for Money. $M_{d}$ and $y_{p}$ here refer to per capita money and income, whereas in the earlier paper they were used to refer to aggregate money and income. The shift was prompted by the desire to simplify the expressions that follow. The same shift is made for all variables referring to money and income. The remaining symbols all have the same meaning here as in ibid.
}

lower-case letters, to magnitudes in real terms or constant prices.

Let us suppose further that estimates of per capita permanent income and permanent prices are compounded of two elements: (I) an expected average annual rate of change to allow for secular trend at a rate of, say, $a_{y}$ for income and $a_{p}$ for prices; (2) a weighted arithmetic or geometric average of past per capita incomes and prices adjusted for such a trend.

For the present, we shall assume that $a_{y}$ and $a_{p}$ are both zero, or alternatively that the actual past record is replaced by the past record adjusted for trends of $a_{y}$ and $a_{p}$ in magnitude. At the present level of discussion, this assumption involves no loss of generality, since the only effect of nonzero values of $\alpha_{y}$ and $\alpha_{p}$ is to add secular trends without affecting cyclical fluctuations. On a more sophisticated level, it would make a difference, since both $a_{y}$ and $a_{p}$ might be variables in the demand function for money, the former since future prospects might modify present demand for money, the latter since it would affect the returns on some alternative assets.

We can then write:

$$
\begin{array}{ll}
\text { (2) } & P_{p}(T)=F[P(t) ; t<T] \\
\text { (3) } & y_{p}(T)=G[y(t) ; t<T],
\end{array}
$$

where $P(t)$ and $y(t)$ are measured prices and measured real income per capita at time $t$, and the functions are to be interpreted as saying that permanent prices and income are functions of the past history of measured income or prices. If we consider discrete data, say, annual data, we can approximate equations 2 and 3 by either

$$
\begin{aligned}
& P_{p}(T)=\sum_{i=0}^{\infty} w_{i}^{\prime} P(T-i)=w_{0}^{\prime} P(T) \\
& \quad+\left(\mathrm{I}-w_{0}^{\prime}\right) P_{p}(T-\mathrm{I}), \\
& y_{p}(T)=\sum_{i=0}^{\infty} w_{i}^{\prime} y(T-i)=w_{0}^{\prime} y(t) \\
& \quad+\left(\mathrm{I}-w_{0}^{\prime}\right) y_{p}(T-\mathrm{I}),
\end{aligned}
$$

where

$$
\Sigma w_{i}^{\prime}=I
$$

or by

$$
\begin{gathered}
\text { (2b) } \log P_{p}(T)=\sum_{i=0}^{\infty} w_{i} \log P(T-i)=w_{0} \log \\
P(T)+\left(1-w_{0}\right) \log P_{p}(T-\mathrm{I}),
\end{gathered}
$$


(3b) $\quad \log y_{p}(T)=\sum_{i=0}^{\infty} w_{i} \log y(T-i)=w_{0}$

where

$$
\log y(T)+\left(1-w_{0}\right) \log y_{p}(T-\mathbf{I})
$$

$$
\Sigma w_{i}=I \text {. }
$$

Note that, in both cases, we have assumed that the same weights are used for income and prices.

Suppose the community is regarded as always being on its demand curve for money. Then an increase in the stock of money will require an increase in permanent income or prices or both sufficient to make the community satisfied with the new stock of money, and these increases can be brought about only by increases in measured income or prices or both. To illustrate: Suppose, for simplicity, real measured income and real permanent income remain unchanged. Then from equation $I$, a one per cent change in $M$ will require a one per cent change in $P_{p}$. But from equation $2 \mathrm{a}$ or $2 \mathrm{~b}$, a one per cent change in $P_{p}$ will require that $P(T)$ rise by more than one per cent, or by $\frac{I}{w_{0}^{\prime}}$ per cent for equation $2 \mathrm{a}$ and $\frac{\mathbf{I}}{w_{0}}$ per cent for equation $2 \mathrm{~b}$. But $w_{0}^{\prime}$ and $w_{0}$ are less than unity. Hence, the percentage rise in measured prices and income will be larger than the percentage rise in money.

To be more specific and to allow for changes in both prices and income, let us replace equation I by a special form we have found to work rather well empirically:

$$
\frac{M}{P_{p}}=\gamma\left(y_{p}\right)^{\delta},
$$

where $\gamma$ and $\delta$ are numerical constants (or, more generally, functions of omitted variables, such as returns on other assets), all the variables are at time $T$, and we have dropped the subscript $d$ from $M$ because of our assumption that the amount demanded is always equal to the amount supplied. In logarithmic form, (4) is

$$
\begin{gathered}
\log M(T)=\log \gamma+\log P_{p}(T) \\
+\delta \log y_{p}(T) .
\end{gathered}
$$

Substitute (2b) and (3b) into (4a), giving

(5) $\log M(T)=\log \gamma+w_{0}(\mathbf{1}-\delta) \log P(T)$

$$
+\delta w_{0} \log Y(T)+\left(1-w_{0}\right)
$$

$\left[\log P_{p}(T-1)+\delta \log y_{p}(T-\mathrm{I})\right]$, where

$$
\log Y(T)=\log y(T)+\log P(T),
$$

i.e., $Y(T)=$ measured income per capita. Replace the final bracket in (5) by its equivalent from (4a) for $T-\mathrm{I}$, namely, $[\log M(T-\mathrm{I})$ $-\log \gamma]$, and then solve (5) for $\log Y(T)$. This gives

$$
\text { (6) } \begin{aligned}
\log Y(T)= & \frac{\mathrm{I}}{\delta w_{0}}\{\log M(T)-\log \gamma \\
- & w_{0}(\mathbf{1}-\delta) \log P(T)-\left(\mathrm{I}-w_{0}\right) \\
& {[\log M(T-\mathrm{I})-\log \gamma]\} . }
\end{aligned}
$$

Differentiate equation 6 with respect to $\log$ $M(T)$, allowing for the fact that $P(T)$ will change along with $Y(T)$. This gives

$$
\text { (7) } \begin{aligned}
\frac{d \log Y(T)}{d \log M(T)} & =\frac{\mathrm{I}}{\delta w_{0}}\left[\mathrm{I}-w_{0}(\mathrm{I}-\delta)\right. \\
\frac{d \log P(T)}{d \log Y(T)} & \left.\times \frac{d \log Y(T)}{d \log M(T)}\right] .
\end{aligned}
$$

Solve for $d \log Y(T) / d \log M(T)$ to get

$$
\text { (8) } \frac{d \log Y(T)}{d \log M(T)}=\frac{\mathbf{I}}{w_{0}[\delta+(\mathbf{I}-\delta) \eta]} \text {, }
$$

where $\eta$ is the elasticity of the measured price level with respect to measured income, and can be expected to be between zero and unity for cyclical fluctuations (i.e., both prices and output can be expected to move in the same direction as money income). We may designate $d \log Y(T) / d \log M(T)$ the money multiplier, analogous to the investment multiplier, though it should be noted that the analogy is somewhat incomplete. The money multiplier gives the ratio of the percentage change in income to the percentage change in the money stock. ${ }^{32}$ To get the number of dollars of income change per dollar change in the stock of money, it is necessary to multiply the money multiplier by the income velocity of money.

It so happens that our earlier work furnishes empirical estimates for the United States of all the quantities entering into the right-hand side of equation 8. Hence, we can construct an estimate of the elasticity of money income with respect to the money stock. These estimates are as follows: ${ }^{38}$

\footnotetext{
${ }^{82}$ Because of the assumption that $a_{y}$ and $a_{P}$ are zero, or alternatively that the actual past record is replaced by the past record adjusted for trend, what is here called a change in the money stock is logically equivalent to a change in the money stock relative to its trend, or to a change in the rate of change.

${ }^{3}$ From Friedman, The Demand for Money. (1) A
} 


$$
\begin{aligned}
w_{0} & =0.33 \\
\delta & =\mathrm{r} .8 \mathrm{I} \\
\eta & =0.20
\end{aligned}
$$

Inserting these figures in equation 8 gives

$$
\text { Estimate } \frac{d \log Y(T)}{d \log M(T)}=\mathrm{I} .84
$$

This estimate is certainly remarkably close to the estimate, based on Table 4 , of the ratio of the variability of income to the variability of money. It will be recalled that we there found this ratio to be almost exactly 2.0. So far as we can see, these two numbers are estimates of the same theoretical construct. ${ }^{34}$ Yet,

value of $\beta=0.4$ implies a weight for the first year of 0.33 ; (2) the value of $\delta$ is from equation 9 of ibid.; (3) the value of $\eta$ is derived from Table 1 of $i b i d$. by dividing the entry for "implicit price deflator" in column (3) by the entry for "money income" in the same column.

With respect to ( $I$ ), it should be noted that permanent income and prices were computed in ibid. by equations $2 \mathrm{a}$ and $3 \mathrm{a}$ rather than $2 \mathrm{~b}$ and $3 \mathrm{~b}$. We have nonetheless taken the resulting value of $w_{0}^{\prime}$ in our present notation as an estimate of $w_{0}$. This is correct as a first approximation, but in further work it would probably be better to work directly with equations $2 b$ and $3 b$.

With respect to (3), the number used is for aggregate money income, not per capita. However, since the number is the difference between the per month rates of rise during expansion and contraction, and since population shows little response to cycles, the per capita figures would be lower by roughly the same amount for expansion and for contraction, and hence the difference would be unaffected.

as One way to see this is to consider the problem of estimating directly the magnitude of the money multiplier from data on actual year-to-year changes in the logarithms of income and money. The first step would be to express the first differences as deviations from some mean values, designed to be the empirical counterparts of our theoretical constructs: $a_{\nu}+a_{p}=$ the expected rate of change in money (permanent) income; and $a_{p}+\delta a_{y}=$ the rate of change in the stock of money that would be consistent with a rate of change of $a_{y}$ in real income and $a_{p}$ in prices. That is, if money income, prices, and the stock of money all changed at exactly these rates, all expectations would be realized and there would be no disturbances to set the money multiplier, as we have defined it, to work. This first step is accomplished in our moving standard deviation analysis by computing, first, moving averages, and then expressing the observed first differences as deviations from the relevant average. Call these deviations from means, $\triangle^{\prime} \log Y$ and $\Delta^{\prime} \log M$.

The second step would be to estimate the mean ratio of $\triangle^{\prime} \log Y$ to $\triangle^{\prime} \log M$. But it would be undesirable to do this by averaging the ratio of the one to the other, since either might on occasion be close to zero (i.e., the variance of the ratio is in principle infinite). It would be better to estimate a value of, say, $K$ in

$$
\triangle^{\prime} \log Y=K \triangle^{\prime} \log M \text {. }
$$

But as a statistical matter, there is no particular reason to prefer the estimate obtained by regressing $\Delta^{\prime} \log \boldsymbol{Y}$ on $\Delta^{\prime} \log M$ to the estimate obtained by regressing $\Delta^{\prime} \log M$ on $\Delta^{\prime} \log Y$. In its rigid form the money multiplier analysis statistically, they are almost completely independent. The estimate in equation 9 comes from the following sources: $w_{0}$ is based on a study of the consumption function which used no data on money whatsoever; $\delta$ is based on a correlation between average cycle bases of money and estimated permanent income; and $\eta$ is based on the ratio of per month cyclical amplitudes computed from average cycle patterns of money income and prices. Hence, so far as we can see, no one of these items uses in any way the intracyclical movements of money. Yet the estimate of 2.0 based on Table 4 has in its denominator the average standard deviation of sets, containing $3,4,5$, or 6 years, of year-to-year percentage changes in the stock of money. The close agreement of two estimates, statistically so independent, certainly strongly suggests that the theoretical structure which produced them deserves further exploration. $^{35}$

In such further exploration it would be desirable to generalize this analysis in a number of respects. (I) $\eta$ should not be treated as a numerical constant. One would expect it to be different at different stages of the cycle and under different circumstances. Under conditions of full employment and inflation, it would be unity or close to it, which - given that $\delta$ is greater than unity - would make the money multiplier a maximum of $\mathrm{I} / w_{0}$, or with our

would imply perfect correlation, so the two regressions would be the same except for statistical errors of estimate. The "correct" regression then depends on the magnitude of errors in $\Delta^{\prime} \log Y$ and $\Delta^{\prime} \log M$. As is well known, the two simple regression coefficients give upper and lower bounds to any estimates obtained by treating both variables as subject to error. The geometric mean of these two bounding estimates is precisely the ratio of the standard deviation of $\Delta^{\prime} \log Y$ to the standard deviation of $\Delta^{\prime} \log$ $M$.

${ }^{35}$ We have used the estimates of $w_{0}, \delta$, and $\eta$ above because they are available in published form. We have been experimenting further with estimating demand equations using annual data instead of cycle bases, and estimating $w_{0}$ internally from the money correlations themselves, rather than externally. This work is still tentative but one set of results may be cited, because they are at the moment the most divergent from those given above.

For the years $1885-1960$, one estimate of $w_{0}$ is 0.22 and of $\delta$ is 2.27 . Inserting these along with $\eta=0.20$ into equation 8 gives an estimate of the money multiplier of 2.25 , or on the other side of the estimate of 2.0 from Table 4. Interestingly enough, this estimate is very close to the ratio, formed from the geometric means of the computed standard deviations, which ranges from 2.13 to 2.3I for different numbers of terms (see footnote 12). 
estimate of $w_{0}, 3$. At the other extreme, if there were extensive unemployment, $\eta$ might be close to zero (though it is by no means clear that this has been true in experience), which would make the money multiplier a minimum of $I / w_{0} \eta$, or with our estimates, I.67. More generally, $\eta$ plays an important role not only in any theory along the general lines we have been sketching but also in income-expenditure theories. ${ }^{36}$ It deserves much more systematic study than it has received. (2) The demand equation 4 should be expanded to include interest rates and perhaps the rate of change in prices. Though our studies suggest that these are far less important than income in affecting the demand for money, interest rates do have a statistically significant effect and, since they have a fairly regular cyclical pattern, should be included in a cyclical analysis. (3) The effect of expected trends in prices and income should be allowed for explicitly and not simply neglected, as we have done. (4) For cycle analysis, the demand equations should be estimated on a quarterly rather than annual basis. (5) In generalizing to a quarterly basis, it will no longer be satisfactory to suppose that actual and desired money balances are always equal. It will be desirable to allow instead for a discrepancy between these two totals, which the holders of balances seek to eliminate at a rate depending on the size of the discrepancy. This will introduce past money balances into the estimated demand equation not only as a proxy for prior permanent incomes but also as a determinant of the discrepancies in the process of being corrected. In addition, it will permit lag patterns other than the simple exponential kind we have used.

\section{A Tentative Sketch of the Mechanism Transmitting Monetary Changes}

However consistent may be the relation between monetary change and economic change, and however strong the evidence for the autonomy of the monetary changes, we shall not be persuaded that the monetary changes are the source of the economic changes unless we can specify in some detail the mechanism that con-

\footnotetext{
${ }^{80}$ See Friedman and Meiselman, "The Relative Stability of Monetary Velocity."
}

nects the one with the other. Though our knowledge is at the moment too meager to enable us to do this at all precisely, it may be worth sketching very broadly some of the possible lines of connection, first, in order to provide a plausible rationalization of our empirical findings; second, to show that a monetary theory of cyclical fluctuations can accommodate a wide variety of other empirical findings about cyclical regularities; and third, to stimulate others to elaborate the theory and render it more specific.

Let us start by defining an Elysian state of moving equilibrium in which real income per capita, the stock of money, and the price level are all changing at constant annual rates. The relation between these rates depends on whether real income is rising or falling, whether wealth is remaining constant as a ratio to income or is rising or falling relative to income, on the behavior of relative rates of return on different forms of wealth, and on the wealth elasticity of demand for money. To simplify, let us suppose that all interest rates in real terms (i.e., adjusted for the rate of change in prices) and also the ratio of wealth to income are constant, so that the wealth elasticity of demand for money can be approximated by the elasticity of demand for money with respect to permanent income. If real income is rising at the rate of $a_{y}$ per year, the stock of money demanded will then be rising at the rate of $\delta a_{y}$ per year, where $\delta$ is the income elasticity of demand for money, and prices will be rising at the rate of $a_{P}=a_{M}-$ $\delta a_{y}$, where $a_{M}$ is the rate of rise in the nominal stock of money per capita. For example, if income per capita is rising at 2 per cent per year, the stock of money at 4 per cent a year, and $\delta$ is $3 / 2$, then prices would be rising at I per cent a year. ${ }^{37}$ If $\delta$ and $a_{y}$ were to be the same, and the stock of money were to rise at, say, ro per cent a year, prices would be rising at the rate of 7 per cent a year; if the stock of money were to be declining at Io per cent a year, prices would be falling at the rate of 13 per cent a year. ${ }^{38}$

\footnotetext{
${ }^{87}$ These are roughly the actual values of $a_{y}, a_{P}$, and $a_{M}$ over the 90 years $1870-1960$ in the U.S. They yield a rather smaller value of $\delta$ (I.5) than we estimate by multiple regression techniques (roughly $I .8$ ).

${ }^{88}$ It may seem strange that a I percentage point difference in the rate of change of the stock of money produces pre-
} 
Let us now suppose that an unexpected rise to a new level occurs in the rate of change in the money stock, and it remains there indefinitely - a single shock, as it were, displacing the time path of the money stock. In tracing the hypothetical effects of the higher rate of growth of the money stock, there will be some difference in detail depending on the source of the increase - whether from gold discoveries, or central bank open-market purchases, or government expenditures financed by fiat money, or a rise in the deposit-currency ratio, or a rise in the deposit-reserve ratio. To be definite, therefore, let us suppose it comes from an increased rate of open-market purchases by a central bank.

Although the initial sellers of the securities purchased by the central bank were willing sellers, this does not mean that they want to hold the proceeds in money indefinitely. The bank offered them a good price, so they sold; they added to their money balances as a temporary step in rearranging their portfolios. If the seller was a commercial bank, it now has larger reserves than it has regarded before as sufficient and will seek to expand its investments and its loans at a greater rate than before. If the seller was not a commercial bank, he is not likely even temporarily to want to hold the proceeds in currency but will deposit them in a commercial bank, thereby, in our fractional reserve system, adding to the bank's reserves relative to its deposits. In either case, therefore, in our system, commercial banks become more liquid. In the second case, in addition, the nonbank seller has a higher ratio of money in his portfolio than he has had hitherto.

Both the nonbank seller and commercial banks will therefore seek to readjust their port-

cisely a 1 percentage point difference in the rate of change of prices regardless of the magnitude of the rate of change of money. Will there not, it is tempting to say, be a flight from money as the rate of change in prices and hence the cost of holding money rises? The answer is that we are comparing states of equilibrium, not the transition from one state to another. In a world in which prices are rising at 7 per cent a year, the stock of money will be smaller relative to income (i.e., velocity will be higher) than it would in a world in which prices are falling at 13 per cent a year. But, in both, velocity will be changing only in response to the change in real income, which is by assumption the same in the two worlds. Of course, it is possible that $\delta$ is different at different levels of cost of holding money; but that would be an effect of a rather subtler kind. folios, the only difference being that the commercial banks will in the process create more money, thereby transmitting the increase in high-powered money to the total money stock. The interposition of the commercial bank in the process means that the increase in the rate of growth of the money stock, which initially was less than in high-powered money, will for a time be greater. So we have here already a mechanism working for some overshooting.

It seems plausible that both nonbank and bank holders of redundant balances will turn first to securities comparable to those they have sold, say, fixed-interest coupon, low-risk obligations. But as they seek to purchase these they will tend to bid up the prices of those issues. Hence they, and also other holders not involved in the initial central bank open-market transactions, will look farther afield: the banks, to their loans; the nonbank holders, to other categories of securities - higher-risk fixedcoupon obligations, equities, real property, and so forth.

As the process continues, the initial impacts are diffused in several respects: first, the range of assets affected widens; second, potential creators of assets now more in demand are induced to react to the better terms on which they can be sold, including business enterprises wishing to engage in capital expansion, house builders or prospective homeowners, consumers who are potential purchasers of durable consumer goods - and so on and on; third, the initially redundant money balances concentrated in the hands of those first affected by the open-market purchases become spread throughout the economy.

As the prices of financial assets are bid up, they become expensive relative to nonfinancial assets, so there is an incentive for individuals and enterprises to seek to bring their actual portfolios into accord with desired portfolios by acquiring nonfinancial assets. This, in turn, tends to make existing nonfinancial assets expensive relative to newly constructed nonfinancial assets. At the same time, the general rise in the price level of nonfinancial assets tends to raise wealth relative to income, and to make the direct acquisition of current services cheaper relative to the purchase of sources of services. These effects raise demand curves for current 
productive services, both for producing new capital goods and for purchasing current services. The monetary stimulus is, in this way, spread from the financial markets to the markets for goods and services.

Two points need emphasis at this stage. The first is that the terms "financial markets," "assets," "investment," "rates of interest" and "portfolio" must, in order to be consistent with the existing empirical evidence, be interpreted much more broadly than they of ten are. It has been common to restrict attention to a small class of marketable financial securities and the real capital it finances, to regard "the" rate of interest as the market yield on such securities, and the "investment" which is affected by changes in the rate of interest as solely or mainly the items classified as "capital formation" in national income accounts. Some of the empirical results summarized earlier are inconsistent with this view. ${ }^{39}$ To rationalize the results, it is necessary to take a much broader view, to regard the relevant portfolios as containing a much wider range of assets, including not only government and private fixed-interest and equity securities traded on major financial markets, but also a host of other assets, even going so far as to include consumer durable goods, consumer inventories of clothing and the like and, maybe also, such human capital as skills acquired through training, and the like. Similarly, it is necessary to make "rate of interest" an equally broad construct, covering explicit or implicit rates on the whole spectrum of assets. ${ }^{40}$

The second point is to note how readily these tentative lines on our sketch accommodate some of the documented regularities of business cycles. The cyclical counterpart to our assumed initial shock is the rise in the rate of growth of the money stock that generally occurs early in contraction. On the basis of the sketch so far, we should expect it to have its first impact on the financial markets, and there, first on bonds, and only later on equities, and only still later on actual flows of payments for real resources. This is of course the actual pattern. The financial markets tend to revive well before

\footnotetext{
${ }^{30}$ In particular, those in Friedman and Meiselman, "The Relative Stability of Monetary Velocity."

${ }^{40}$ See ibid. for a fuller discussion of these points.
}

the trough. Historically, railroad bond prices have risen very early in the process. Equity markets start to recover later but still generally before the business trough. Actual expenditures on purchases of goods and services rise still later. The consistent tendency for orders to lead actual purchases would of course be expected on this theory, but it would follow simply from the mechanics of the production process. Hence it gives no definite support to this or any other theory. It is simply a stage in the way any impulse, however generated, will be transmitted. The tendency for the prices of financial assets to rise early in the pattern is quite a different matter. If the initial impulse were generated by an autonomous increase in spending on final goods and services, it would be plausible to expect the timing to be the reverse of what it actually is. Of course, on the theory being sketched, the precise timing will depend on the source of the initial monetary impulse. However, under the banking structure of the United States and other financially developed countries, whatever the initial impulse, commercial banks will play a key role in transforming it into an increased rate of growth in the money stock, and this will impose a large measure of uniformity on the outcome.

One other feature of cyclical experience that our sketch may be able to rationalize and that is worthy of special note is the behavior of the deposit-currency ratio. The initial monetary impulse is concentrated among holders of financial assets and is then diffused to the rest of the community. But this means, as we have noted, that the redundant balances are initially in the hands of asset holders with a high ratio of deposits to currency. As the redundant balances are diffused, they spread to more nearly a representative group in the population. Consistently with this sequence, the ratio of deposits to currency starts to rise early in contraction, not very far removed in time from the trough in the rate of rise in the money stock; the deposit-currency ratio continues to rise during the rest of contraction and early expansion but then reaches a peak around mid-expansion, and falls. The turning point, on this sketch, reflects the point at which the net tide of redundant balances has shifted from the financial community to the rest of the community. 
To return to our sketch, we had reached the stage at which the demand for the services of factors of production was rising, which means, of course, a rise in money incomes. This will tend to be partly reflected in a rise of the prices of resources and of final goods; at the same time, the prices of nonfinancial assets will already have been rising as demand shifted to them from financial assets. These price rises themselves tend to correct portfolios by making the real value of monetary assets less than they otherwise would be. The result is to reduce the relative redundancy of monetary assets, which sets the stage for a rise in the structure of interest rates in place of the prior decline. The exact sequence of rises in prices, whether it affects first prices of final products, and only later prices of factors and so shifts profit margins - and so on - depends on the structure of the product and factor markets. Like the relation between new orders and production, this is part of the transmission mechanism common to all theories and tells little or nothing about the generating impulse. This does not mean it is unimportant. On the contrary, it may well determine the sequence of events once the stage is reached at which income is rising, as well as the time duration of subsequent reactions.

However, the important point for our purposes is very different. It is that the process we have described will tend to overshoot the mark; it will not simply produce a smooth movement to the new path consistent with the new rate of growth of the money stock assumed to prevail. There are two classes of reasons embodied in our analysis that explain why the process will overshoot. One, and in our view the more basic theoretically, has to do with the demand for money. At the higher rate of price rise that is the new ultimate equilibrium, the amount of money demanded will be less in real terms than it was initially, relative to wealth and hence income. But this means that, in the process of going from the initial to the new equilibrium, prices must rise at a faster rate than their ultimate rate. Hence the rate of price rise must overshoot. This effect is reinforced by that embodied in the subsection, "Conclusions for Major Movements." In the initial stages of the process, money holders overestimate the extent of monetary redundancy, since they evaluate money stocks at unduly low levels of prices; they are slow, that is, to revise their estimates of permanent prices upward, hence they initially seek more radical readjustments in their portfolios than will ultimately turn out to be required. (If this analysis is applied to a cyclical process rather than to our special case of a shift from one moving equilibrium to another, a second element from that part of the section would also enter to produce overshooting - a slow revision of estimates of permanent real income.) The second class of reasons for overshooting has to do with feedback effects through the monetary mechanism. Two of these have already been mentioned. First, the effect of the initial assumed shock is to cause a greater rate of rise in high-powered money than in the money stock as a whole. But since there is nothing about the shock that will permanently alter the ratio of money to high-powered money, it follows that the money stock must for a time grow faster than ultimately in order to catch up. Second, there is reason for the depositcurrency ratio to rise in the initial stages of the process above its long-run equilibrium level. In addition to these two classes of reasons for overshooting, which derive from the specifically monetary elements in our sketch, there may of course be those arising from the other elements of the transmission mechanism common to almost any theory.

The tendency to overshoot means that the dynamic process of transition from one equilibrium path to another involves a cyclical adjustment process. Presumably, these cyclical adjustments will be damped, though no merely verbal exposition can suffice to assure that the particular mechanism described will have that property. Presumably also, the extent of overshooting will not be negligible relative to the disturbance, though again no merely verbal exposition can suffice to assure that the mechanism described will have that property.

The passage from this analysis of a single displacement of the rate of growth of money to a monetary theory of partly self-generating cyclical fluctuations is direct and has in large part been embodied in the preceding statement. It may be worth noting, however, that it would be rather more plausible to suppose a 
shock to take the form of an unusually high or low rate of growth of the stock of money for some time, with a reversion to a previous level rather than a shift to a permanently new level. Such a shock is equivalent to two shocks of the kind we have been considering - but shocks in opposite directions. Hence the shock itself gives rise to a cyclical movement in addition to the cyclical adjustment to each shock separately. The fact that in the cycle there is never that complete adjustment to the existing state of affairs that is present in the assumed initial Elysian state of moving equilibrium is of no decisive importance. It merely means that one state of incomplete adjustment succeeds another and that successive widenings and narrowings of discrepancies between actual and desired portfolios replace the introduction of a discrepancy and the correction of it. As noted parenthetically earlier, of somewhat more moment are the fluctuations in real income and employment over the cycle, which introduce an important reason for overshooting.

The central element in the transmission mechanism, as we have outlined it, is the concept of cyclical fluctuations as the outcome of balance sheet adjustments, as the effects on flows of adjustments between desired and actual stocks. It is this interconnection of stocks and flows that stretches the effect of shocks out in time, produces a diffusion over different economic categories, and gives rise to cyclical reaction mechanisms. The stocks serve as buffers or shock absorbers of initial changes in rates of flow, by expanding or contracting from their "normal" or "natural" or "desired" state, and then slowly alter other flows as holders try to regain that state.

In this stock-flow view, money is a stock in a portfolio of assets, like the stocks of financial assets, or houses, or buildings, or inventories, or people, or skills. It yields a flow of services as these other assets do; it is also subject to increase or decrease through inflows and outflows, also as the other assets are. It is because our thinking has increasingly moved in this direction that it has become natural to us to regard the rate of change in the stock of money as comparable to income flows and to regard changes in the rate of change as a gen- erating force in producing cyclical fluctuations in economic activity.

\section{Summary}

The statistical evidence on the role of money in business cycles assembled in the first section demonstrates beyond any reasonable doubt that the stock of money displays a systematic cyclical behavior. The rate of change in the money stock regularly reaches a peak before the reference peak and a trough before the reference trough, though the lead is rather variable. The amplitude of the cyclical movement in money is closely correlated with the amplitude of the cyclical movement in general business and is about half as large as the amplitude of cyclical movements in money income. The most important single determinant, from the supply side, of the cyclical pattern of money is the cyclical pattern in the division of the public's money holdings between currency and deposits. The stock of money is much more closely and systematically related to income over business cycles than is investment or autonomous expenditures.

In the second section we suggested plausible interpretations of these facts, pointing out that the close relation tells nothing directly about whether the cyclical changes in money are simply a consequence of the changes in income or are in large measure the source of those changes. For major movements in income, we concluded that there is an extremely strong case for the proposition that sizable changes in the rate of change in the money stock are a necessary and sufficient condition for sizable changes in the rate of change in money income. For minor movements, we concluded that, while the evidence was far less strong, it is plausible to suppose that changes in the stock of money played an important independent role, though certainly the evidence for these minor movements does not rule out other interpretations. In the subsection, "Conclusions for Major Movements," we formalized one element of a theory designed to account for the observed tendency of cyclical fluctuations in income to be wider in amplitude than cyclical fluctuations in money are. The theory, plus earlier empirical work, yielded an independent 
statistical estimate of what we call the money multiplier, or the ratio of the percentage change in income to the associated percentage change in the stock of money. The independent estimate was $\mathrm{r} .84$; the directly observed ratio 2.o. This agreement does not reflect any common statistical origin of the two estimates. It therefore suggests that further elaboration of the theory might be well worthwhile.

Finally, in the last section, we sketched in broad strokes the kind of transmission mechanism that could explain how monetary changes can produce cyclical fluctuations in income, and that is consistent with our knowledge of economic interrelationships. The final pic- ture that might ultimately develop out of this sketch could be of a partly self-generating cyclical mechanism. Disturbances in the rate of change in the money stock set in train a cyclical adjustment mechanism including a feedback in the rate of change in money itself. Additional disturbances from time to time would prevent the fluctuations from dying out. The mechanism emphasizes the reciprocal adjustment of stocks to flows, with money playing a key role as a component of the stock of assets. We emphasize that this sketch is exceedingly tentative and, of course, not preclusive. The mechanism outlined can be combined with other adjustment mechanisms.

\section{COMMENT}

Hyman P. Minsky, University of California, Berkeley

Friedman and Schwartz examine monetary factors in economic fluctuations. Monetary factors are narrowly defined as ". . . the role of the stock of money and changes in the stock." The authors cast "the 'credit' market as one of the supporting players rather than a star performer." Apparently the plot was changed after the show was cast for, with the possible exception of the last section of the paper ("A Tentative Sketch of the Mechanism Transmitting Monetary Changes"), where portfolio adjustments are introduced in a not very precise way into the discussion of the channels by which monetary changes lead to output changes, credit has a walk-on rather than a supporting role. Since the authors cite Fisher as authority for the "dance of the dollar" view of business cycles, we can suppose they are familiar with and chose to ignore Fisher's "debt deflation" view of business cycles in which the behavior of the capital and credit markets is a star performer in generating deep depressions. ${ }^{1}$

The proposition Friedman and Schwartz assert to be true is that the business cycles of experience - chronicled by the National $\mathrm{Bu}$ reau of Economic Research reference cycles -

\footnotetext{
${ }^{1}$ I. Fisher: Booms and Depressions, New York, 1932; idem, "The Debt-Deflation Theory of Great Depressions," Econometrica, Oct. 1933, pp. 337-357.
}

can be explained in the sense of being caused by the behavior of the money supply. According to their view, however, the monetary event that calls the tune for economic activity is neither the supply of money nor a change in the supply of money; rather, it is a change in the rate of change in the supply of money that is the critical variable. The accelerator view of the way in which monetary changes operate to affect economic activity can be linked to an accelerator formulation of business cycle behavior quite easily by way of the need to finance externally part of the induced investment during periods of expansion. ${ }^{2}$ As the authors show no interest in integrating their explorations of the supply of money with an income-expenditure view of business cycles, this possibility is ignored.

The authors make their point of view clear when, in commenting upon the recent revival of interest in monetary policy, they assert "this fair-weather source of support for the importance of money is a weak reed." Belief in a narrowly defined monetary explanation of business cycles is implicitly a matter of ideological importance. Hence we can expect the authors to engage in a hard sell of a point of view. In the process of selling their viewpoint the authors invent "plausible interpretations of the factual evidence" and "a plausible ra-

${ }^{2}$ H. P. Minsky: "Monetary Systems and Accelerator Models," American Economic Review, Dec. I957, pp. 859883. 
tionalization of our empirical findings," they cite as supporting evidence both work in progress and material not generally available, and they ignore evidence that does not support their views, such as the fiscal relations in the 1937-38 recession and the success of short-run forecasting models which place little or no emphasis upon monetary phenomena.

The Friedman and Schwartz paper contains a number of ingenious studies and constructions, some of which I feel sure will prove to be of lasting value. However, the argument does not depend solely upon these studies; it is also based upon their reading of history and the relations they derive between changes in the rate of change in the stock of money as given by their time series (money to them almost always includes time deposits in commercial banks) and the National Bureau's reference cycle chronology.

Two classes of business cycles, mild and deep depression cycles, are identified. Twentyone business cycles are recorded as occurring between 1870 and 1960 , of which six were deep depression cycles. The mild depression cycles are associated by the authors with increases and decreases in the positive rate of growth of the money supply, whereas the deep depression cycles are associated with significant decreases in the money supply. ${ }^{3}$ Two of the decreases in the stock of money, those of I9r9-20 and 1937-38, can be identified as the result of specific actions by the Federal Reserve System. Neither of the administered decreases in the money stock was associated with a financial crisis or panic. In the other four deep depression cycles a monetary-financial crisis was part of the process by which the money supply was decreased. An explanation which makes financial crises endogenous rather than exogenous events seems to be required to complete the monetary explanation of business cycles.

\footnotetext{
"Friedman and Schwartz associate two "mild" declines in the money stock (1948-49 and r959-60) with mild business contractions. Those mild declines were about one-half as large as the smallest of the declines they consider to be significant. On the other hand, the largest of the decreases they consider to be significant was about 15 times as large as the smallest "significant" one (all decreases are measured as a percentage decline in the money stock). The authors do not explain why the break between mild and deep depressions has been associated with the difference between I. 3 per cent and 2.4 per cent declines in the money supply.
}

To one who remembers Schumpeter's Kitchen, Juglar, and Kondratief cycles, the chronology of major and minor cycles in the Friedman and Schwartz paper recalls the phrase "3 Kitchens and then a Juglar," for three mild depression cycles separated the deep depression cycles following 1873, 1893, 1907 and 1920 , and two mild recession cycles occurred between the deep depression cycles that began in I920 and I929. The I929 and I 937 deep depression cycles were not separated by any mild depression cycles. As the declines in the money supply associated with the 1920 and the 1937 contractions can be related to administrative actions, the deviation from the Schumpeterian sequence in the post-World War I period can be laid to the effects of intervention. The chronology of major and minor cycles lends some weight to the proposition that the necessary conditions for a financial crisis emerge as a result of the financial relations that develop during an extended period in which growth is interrupted only by mild depressions. The events since 1920 indicate that the sequence of events leading to severe business cycles can be modified by central bank action: the hope is that, with increased knowledge, lender-of-last-resort acts by the central bank can prevent serious financial crises.

I have organized the body of my comments on the Friedman and Schwartz paper around two topics, the importance of money and the transmission mechanism.

\section{The Importance of Money}

Friedman and Schwartz argue that "money is important." This slogan can be interpreted in a number of ways. The belief that money is important is not inconsistent with acceptance of the basic validity of the modern incomeexpenditure approach to business cycles. To one holding such a view, the nonexistent or primitive monetary and financial system incorporated in income and expenditure models such as those of Duesenberry, Eckstein, and Fromm, of Klein, and of Suits ${ }^{4}$ is a defect that should

'J. S. Duesenberry, O. Eckstein, and G. Fromm, "A Simulation of the United States Economy in Recession," Econometrica, Oct. I960, pp. 749-809. There are many Klein models, one of the most recent is L. Klein, "A Postwar Quarterly Model: Description and Applications," pre- 
be corrected. Holders of this position with respect to the importance of money would argue that serious work on monetary and financial interrelations is needed in order to improve upon what we now know. Even though the current models are adequate predictors of short and relatively mild movements of income and so forth, they are deficient, because in their present form they are not able to generate the more extreme movements characteristic of deep depressions and inflations. The conjecture guiding research would be that the completion of these models, so that they could encompass such broader possibilities, would entail the use of a more sophisticated model of money and finance: in particular relations which state how money and financial institutions behave, and how portfolio adjustments and financial liabilities affect the various sectors would have to be incorporated into the more complete model.

Another interpretation of the phrase "money is important" would reject the basic validity of the income-expenditure approach. The observed path of money income and prices is interpreted as the result of shocks imposed upon an otherwise inherently stable growth process by random or systematic changes in either the nominal quantity of money or the rate of change in the money supply. In this view, the introduction of a money supply that behaves in the correct manner would eliminate either all or at least a large part of those disturbances that constitute the major malfunctioning of an enterprise system. The effects of changes in the stock of money and changes in the rate of changes in the stock of money are independent of the financial interrelations underlying the monetary system, as well as of the other financial usages and institutions which exist. Basically, the nominal supply of money calls the tune and money income and prices follow, perhaps with a lag.

Almost always Friedman and Schwartz seem to adopt the second interpretation of the importance of money and they thereby reject the validity of the income-expenditure approach to business cycles. However, at times they do

pared for an NBER conference on Research in Income and Wealth, 1962. D. B. Suits, "Forecasting with an Econometric Model," American Economic Review, Mar. I962, pp. IO4-I32. come within hailing distance of the first interpretation, particularly when they assert: "Clearly the view that monetary change is important does not preclude the existence of other factors that affect the course of business or that account for the quasi-rhythmical character of business fluctuations. We have no doubt that other factors play a role."

They go on to state:

A fully satisfactory explanation of the minor movements would require an explicit and rigorously stated theory, which could take the form of a series of simultaneous differential equations describing the reaction mechanism of the economy, together with a specification of the joint distribution function of the random disturbances impinging on it, and a specification of the systematic disturbances that could be introduced into it. Our belief that money plays an important role in minor movements is equivalent to asserting that some of the differential equations would contain the stock of money as a variable, that disturbances in the stock of money are among the random or systematic disturbances impinging upon the system, and that these disturbances alone would be capable of generating a path for such major economic variables as money income, prices, output and the like, comparable to the path they actually follow during mild depression cycles.

The first sentence of this quotation is of course a statement of the content of the income-expenditure prediction models. The conjecture that ". . . these [monetary] disturbances alone would be capable of generating a path ... comparable ..." to the observed path could be interpreted as a hypothesis to be tested within a specific income-expenditure model. I happen to believe that the introduction of monetary and the related financial phenomena only by way of the stock of money as a variable in the equation system would turn out to be not tenable; that any serious work on monetary phenomena in relation to business cycles will result in the inclusion in the system of variables and equations that reflect not only the money stock but also the asset structure of the monetary authorities and the financial liabilities of other units. Nevertheless, the view expressed in the above quotation of the role of money in determining system behavior is within working-hypothesis distance of the income-expenditure approach.

However, the dominant theme of Friedman and Schwartz is that a complex simultaneous 
equation system is not needed in order to understand the essential business-cycle properties of the economy.

There seems to us, accordingly, to be an extraordinarily strong case for the propositions that (I) appreciable changes in the rate of growth of the stock of money are a necessary and sufficient condition for appreciable changes in the rate of growth of money income; and (2) that this is true both for long secular changes and also for changes over periods roughly the length of business cycles. To go beyond the evidence and discussion thus far presented: our survey of experience leads us to conjecture that the longerperiod changes in money income produced by a changed secular rate of growth of the money stock are reflected mainly in different price behavior rather than in different rates of growth of output; whereas the shorterperiod changes in the rate of growth of money stock are capable of exerting a sizeable influence on the rate of growth of output as well.

The more modest view of the part played by the stock of money and changes in the stock of money is taken when Friedman and Schwartz discuss minor movements; the stronger view is taken when they discuss major movements. However, they argue: "If money plays an independent role in major movements, is it likely to be almost passive in minor movements? The minor movements can be interpreted as less virulent members of the same species as the major movements. Is not a common explanation for both more appealing than separate explanations, especially when there is no welltested alternative separate explanation?" If both major and minor movements are to be explained by the same process, then either both are generated by a complex interdependent system in which nonmonetary factors are capable of generating the observed movements, or both are generated by random or systematic shocks from the supply of money. Another of their statements requires comment: "The case for a monetary explanation is not nearly so strong for the minor U.S. economic fluctuations ..." and for minor movements they cannot rule out ". . . the possibility that the close relation between money and business reflected primarily the influence of business on money." It seems to me that Friedman and Schwartz really have to choose between accepting a dual theory, in which major fluctuations are something different from minor fluctuations or, if they insist upon a theory that covers both major and minor cycles, they can accept a view that factors other than the narrowly monetary phenomena are important in generating both types of business cycles.

I believe the adoption of the middle ground between the Friedman and Schwartz position and the models that operate with a skeletal monetary and financial system would be a most fruitful research strategy. The working hypothesis should take the form of a model that integrates a more complete monetary and financial system into an income-expenditure framework, in particular, financial commitments along with financial assets should be integrated into the various behavior equations. One aim of such an integrated model would be to explain what is admittedly an open aspect of the Friedman and Schwartz narrow monetary interpretation of business cycles, which is that "It leaves open the reasons for the change in the rate of growth of the money stock and, indeed, at this point is highly eclectic, taking account of the fact that historically there have been many different reasons." That is, an objective of such a more complete model would be to explain not only money income but also how monetary and financial crises are generated.

Elsewhere I have worked with a model in which the need to deficit finance private investment during a period of sustained growth (a period in which economic growth is interrupted by only mild recessions) results in an everincreasing portion of income flows being needed to service financial commitments. ${ }^{5}$ Such changing relations between income receipts and payments due to financial commitments generate an unstable situation in which a not abnormal initial decline in income can explode, by way of financial repercussions, into a major decline in income. The not abnormal initial decline in income, which triggers the large movement of financial variables, is explained by a dynamic income-flow model. In such a model the modest income-induced changes in the rate of change in money, that give pause to Friedman and Schwartz when they assess the role of money in

${ }^{5}$ H. P. Minsky, "Financial Crises, Financial Systems and the Performance of the Economy," to appear in Privale Capital Markets, Vol. XVI, The Supporting Papers, Commission on Money and Credit. 
minor cycles, can be one of a number of elements that may generate the not abnormal initiating decline in income.

Once the financial repercussions of the need to deficit finance private investment are known, we are in a position to investigate whether the financial impact necessary to generate a severe depression can occur in the absence of a marked decline in the money supply. Can a serious debt deflation occur even though the nominal supply of money remains constant or expands? An implication of the Friedman and Schwartz explanation of business cycles is that, even if sharp declines in asset prices and net worth occur owing to a financial crisis centering around the nonmonetary part of the financial system, no serious depression will take place, for they assert that without a large decline in the nominal money supply no deep depression can occur.

\section{The Transmission Mechanism}

Friedman and Schwartz say, ". . . we shall not be persuaded that the monetary changes are the source of economic changes unless we can specify in some detail the mechanism that connects the one with the other." The market processes they specify as connecting the two are consistent with the liquidity-preference doctrine as to how money affects income. To this reader, the connections they specify decrease the difference between a monetary and an income-expenditure explanation of business cycles, almost to the point where it is a matter of the specification of the interest elasticity of various classes of expenditures.

An empirical finding of Friedman and Schwartz is that the changes in the rate of change in the money supply have a long and rather variable lead over the business cycle peaks and troughs. In order to generate such lags, the authors believe that the connection between money and demand must be complex; the mechanism they sketch requires that various financial and real markets be affected by repercussions of the initiating monetary change before income responds. Any process that results in such long and variable leads can also result in considerable slippage between monetary changes and the presumably resultant changes in income. As Keynes put it, "If however we are tempted to assert that money is the drink which stimulates the system to activity, we must remind ourselves that there may be several slips between the cup and the lip" (The General Theory of Employment, Interest and Money, New York, I963, p. I73).

The relevant question in regard to the significance of monetary changes is whether the lag (and slippage) of income changes following changes in the money stock (or its rate of change) is so large and variable that it is not feasible, under all circumstances, to operate on the money stock in order to achieve desired changes in income. But the feasibility of using changes in the money supply to affect income depends upon the channels through which a monetary change affects income. (In what follows I shall be examining an increase in the money supply, or in its rate of change: the argument for a decrease is quite similar aside from the possibility of a liquidity crisis.)

Two models of how bank operations change the supply of money can be distinguished: these can be labeled the open market and the commercial loan ${ }^{6}$ models. Open market operations by banks and monetary authorities result in changes in the money supply due to a substitution of money for income-earning assets in portfolios. Aside from the effects of interest rate changes, no change in the total value of the assets and the financial liabilities of the other sectors result. Commercial loan operations result in changes in the money supply due to acquisition by the banks and authorities of newly created financial liabilities of other sectors. The consolidated financial assets and liabilities of these other sectors change with the money supply. ${ }^{7}$

In addition to the open market and commercial loan routes to a change in the money stock, the money stock can be changed by the production of the monetary commodity (either by mining or international trade) and the creation of fiat money. Aside from the creation of

\footnotetext{
${ }^{6}$ I am not happy with this label.

${ }^{2}$ Commercial loan operations include, not only business lending by banks and rediscounting by the monetary authorities of business paper, but also acquisition by banks and authorities of corporate and government bonds, mortgages, etc., either directly from the issuer or from a financial intermediary which functions as an underwriter or broker.
} 
fiat money to pay off government debt - which as far as I know has not taken place in the United States since 1870 - the link between changes in the money supply by these techniques and changes in demand is direct. ${ }^{8}$ Hence these ways of changing the money supply are in terms of their direct effect upon income quite analagous to commercial loan operations; the analogy breaks down, in that no increase in private debt accompanies these changes.

Throughout most of the period under consideration the United States was on a gold standard-commercial loan monetary system; open market operations were utilized by commercial banks and the central bank for only relatively short periods, when the demand for new financing was not sufficiently vigorous to utilize the commercial banks' ability to acquire assets. Since World War II the United States has been on a mixed open market operationscommercial loan monetary system, in which the Federal Reserve System has affected reserves of commercial banks by purchasing government debt from the market and, on the whole, the commercial banks have acquired newly created private debt. (Commercial banks have engaged in open market purchases during recessions and open market sales and commercial loan operations during expansions. The resulting trend has shown a net change in commercial bank liabilities, offset by assets which were acquired as the result of commercial loan operations.) The only recent period in which both monetary institutions operated mainly by way of open market purchases was following the 1929 crash (although the increasing national debt and the various silver purchasing acts gave the operations some of the characteristics of commercial loan operations).

Friedman and Schwartz state: "The most important [evidence in support of the monetary explanation of business cycles] is the fact that the relation between money and business has remained largely unchanged over a period that has seen substantial changes in the arrangements determining the quantity of money. During part of the period, the United

\footnotetext{
${ }^{8}$ An increase in the money supply by means of a gold flow that results in portfolio investment within the recipient country by the gold importer - such as occurred during the hot money epoch of the I930's - is analogous to an open market rather than to a commercial loan operation.
}

States was on an effective gold standard, during part, on an inconvertible paper standard with floating exchange rates, during part, on a managed paper standard with fixed exchange rates. The commercial banking system changed its role and scope greatly. The government arrangements for monetary control altered, the Federal Reserve System replacing the Treasury as the formal center of control. And the criteria of control adopted by the monetary authorities altered." The above changes are mostly irrelevant to the relation between monetary changes and aggregate demand; they are primarily legal and organizational. (I do not know what Friedman and Schwartz mean by "The commercial banking system changed its role and scope greatly.") Throughout that period, the largest part of the increases in the money stock was associated with the acquisition by the banks of newly created financial assets; almost always, the largest portion of these financial assets were the liabilities of private units; and almost always these financial assets, acquired in exchange for net changes in the money supply, were linked with investment expenditures or the holding of capital goods or financial assets. No matter how substantial the institutional and organizational changes have been, they have not seriously affected the economic relations underlying a change in the money supply: the largest part of the change in the money stock throughout the period was the result of commercial loan operations by commercial banks.

Following open market operations, the channel connecting the monetary change and a change in income involves portfolio adjustments and changes in relative prices. In order to generate an increase in private-sector demand, either the price of services must fall relative to the price of assets, which may lead to an increase in consumption demand; or the price of secondhand nonfinancial assets must rise relative to the price of new assets, which may lead to an increase in investment demand. What happens to the demand for services depends not only upon what is happening to the interest rate but also upon what is happening to consumers' disposable income or, if you wish, to consumers' views as to what is happening to their "permanent" income. The rise in the price of second- 
hand nonfinancial assets relative to new nonfinancial assets will generate an increase in investment only if, after the increase, the price of secondhand assets is not appreciably lower than the price of new assets. Given that the rate of decline in asset prices during the initial stages of a serious depression is greater than the rate of decline in money wages, a sharp fall in income will result in a price level of secondhand assets that is low relative to the production cost of new assets. Hence, a significant rise in investment demand cannot be expected to follow closely upon a modest rise in the relative price of used as compared with new assets such as would result from a fall in interest rates. The recovery of investment in such circumstances will follow upon the more marked rise in the relative price of used as against new assets, owing to the effects of the elimination of excess capacity by way of depreciation and obsolescence, all of which operate quite independently of interest rate changes. That is, the relevant investment demand functions will not be interest elastic but will be responsive to factors that fit naturally into an income-expenditure framework. ${ }^{9}$

Following commercial loan operations by the monetary authorities and commercial banks, the connection between a change in the money supply and a change in income is direct. The units which generate the newly created liabilities acquired by the monetary system will do so because they wish to purchase either financial or real assets. The portfolio adjustment portion of the connection between a monetary change and a change in income is not operative in the initial stages of the adjustment following a commercial loan operation. The channel between an increase in money and a net increase

\footnotetext{
${ }^{8}$ When Friedman and Schwartz trace the effects of an initial open market operation, their starting point is "an Elysian State of moving equilibrium." From such an initial condition the change in relative prices associated with interest rate changes will have an effect upon demand. If the initial conditions include large price differences between the market price of used and the production costs of new capital goods, such as can be expected to exist after a sharp fall in income, then as has been argued in the text, the relative price changes following an open market operation increase in the money supply, will not have an appreciable effect upon demand. We therefore have a world in which the reaction to a monetary change depends upon the initial conditions; which is one of the major attributes of the Keynesian view.
}

in the money value of financial and real assets held by the borrowers is direct. As we are considering a net increase in assets, unless the monetary change is wholely absorbed by a rise in asset prices, additional real or financial assets must be created in exchange for the money spent by the initial borrowing unit. The creation of new real assets is of course investment. Typically, a monetary change resulting from a commercial loan operation enables the borrower to make a real or financial market "demand" effective. The route connecting monetary and income changes is direct; the lag between the monetary change and the initial change in demand will be short and the slippage slight. Of course the full impact of the monetary change will be lagged behind the initial increase in the money supply, but this is fully consistent with the multiplier process.

Given that a strong demand for funds to finance investment exists and that a portion of the supply of such funds has been the result of monetary changes, a decrease in the rate of increase of the money supply will result in an increase in the pressure to finance investment from other sources. In addition to the net flow of savings and the net debt acquisition by the monetary system, the substitution of incomeearning assets for money is a source of financing for investment. Velocity increasingliquidity decreasing portfolio changes will follow a decrease in the rate of increase in the money supply. This is consistent with the Friedman and Schwartz findings that velocity conforms to the reference cycles (Chart 6), whereas the rate of change in the money supply leads (Chart 4) the reference cycles.

Of course the commercial loan model of how the money supply changes begs the question of what determines the strong demand for funds to finance investment. Friedman and Schwartz implicitly assume that a strong investment demand exists when they start from a position of moving equilibrium, and they also assume that this investment demand is elastic with respect to relative interest rates. To an income-expenditure theorist, the existence of a strong demand for funds to finance investment to which a commercial loan monetary system responds requires explanation. On the basis of the observed overall success of the economy, it is easy to assume 
that the flow of technical progress and the feedback from past demands has been on the whole sufficient to generate a buoyant investment demand. However, a corollary of the view that nonmonetary factors have generated a strong investment demand throughout most of the period under consideration is that the income and financial past of an economy can lead to a weak investment demand, and a temporary "saturation" of capital can exist. ${ }^{10}$

Friedman and Schwartz, in their example, specify that the initial change in the rate of change in the money supply is the result of central bank open market operations. Even though they recognize that ". . . whatever the initial impulse, commercial banks will play a key role in transforming it into an increased rate of growth in the money stock . . .," their transmission mechanism operates mainly through portfolio changes which are associated with changes "covering explicit or implicit (interest) rates on the whole spectrum of assets." They pay no attenton to the nature of the assets acquired by the commercial banks. A transmission mechanism which operates by way of financial markets and portfolio changes is fully consistent with the income-expenditure approach, but the effect upon income that Friedman and Schwartz state exists depends upon a strong reaction to small differences in relative interest rates.

Even though the commercial loan model of how the money supply changes yields a more direct linkage between monetary changes and income changes than the open market operations model, it has properties that are inconsistent with the narrow monetary view of business cycles that Friedman and Schwartz espouse. The link between business debt and the money supply is direct in the commercial loan view of the monetary system: hence a feedback from debt to investment demand is an endogenous repercussion in the money creation process. In addition, the combination of a strong investment demand, a money supply linked with the financing of private investment, the additional possibility of financing invest-

${ }^{10}$ Saturation is really not an accurate label for a situation during a severe depression, for the excess supply of capital goods is the result of the fall of incomes substantially below past incomes. Once demand recovers, such "saturation" vanishes. ment by velocity increasing-liquidity decreasing portfolio changes, and the effect upon equity and real asset prices of a long run without a major recession can easily lead to a view that deep depressions are the result of the development of an unstable debt structure during periods in which the economy is a success. Instead of autonomous monetary changes leading to deep depressions, the monetary changes are a result of the debt deflation process of which Fisher wrote, and the debt deflation is the result of an unstable debt structure generated in the process of financing investment during a period in which sustained growth is interrupted by only mild recessions. ${ }^{11}$

Incidentally, Friedman and Schwartz do not try to explain the variability of the length of the lag between a monetary change and the presumably related income change. I conjecture that an explanation of this phenomena would center around the actual mix of operations by which the money supply is changed. This conjecture is inconsistent with the Friedman and Schwartz view that money is money for, if it is true, the effect of a change in the quantity of money or its rate of change does depend upon both the process by which the money supply is changed and the assets acquired by the money system. ${ }^{12}$

Thus, whether we take an open market or a commercial loan view of how the money supply is changed, the market processes which follow are not always satisfactory from the authors' point of view. With an open market monetary system the required investment and consumption reaction will not always take place; with a commercial loan monetary system the develop-

\footnotetext{
11 "There may be equilibrium which, though stable, is so delicately poised that, after departure from it beyond certain limits, instability ensues, just as, at first, a stick may bend under strain, ready all the time to bend back, until a certain point is reached, when it breaks. This simile probably applies when a debtor goes "broke," or when the breaking of many debtors constitutes a "crash," after which there is no coming back to the original equilibrium." I. Fisher, "The Debt-Deflation Theory of Great Depressions," Econometrica, Oct. I933, p. 339.

${ }^{12}$ The authors recognize that the effects of a higher rate of growth of the money supply will differ in detail "depending on the source of the increase," but the sources they mention are sources of commercial bank reserves or are determinants of the efficacy of a given amount of reserves. They never examine the effects of the assets acquired by commercial banks and monetary authorities on future demand.
} 
ing private debt structure can feed back upon future demand for financing. In addition, a commercial loan monetary system is consistent with a debt deflation view of how major recessions are generated: a view in which the historically observed changes in the money supply, particularly those associated with deep depression, are a result of business behavior.

\section{Conclusion}

I have not commended Friedman and Schwartz for the many fine and nice points in their paper. I fully expect that much of their work will become a part of the body of knowledge that all workers in money will accept as valid. Nevertheless, I feel they have failed to make a convincing case for the strong view that monetary changes fully explain observed business cycles. If all they wish to assert is that a fuller integration of monetary phenomena into the basically income-expenditure models would improve these models, then I am sure that there is wide agreement with Friedman and Schwartz. But if this more modest view is their position then I wonder what all the shouting is about.

\section{Arthur M. OKun,}

Yale University

"Money and Business Cycles" is an important addition to previous studies by Friedman and his associates on the relationship between the stock of money and the level of economic activity. The empirical findings offered by Friedman and Schwartz are impressive. Nobody can justly quarrel with their claim that the paper "demonstrates beyond any reasonable doubt that the stock of money displays a systematic cyclical behavior." But, as the authors point out with care and clarity, these empirical results are just as consistent with the view that changes in aggregate activity influence the money supply as they are with the position that changes in the money supply affect economic activity. While we can all agree that the lines of causation run in both directions, the key conclusion of their paper is that the causality runs substantially from money to income, substantially enough to warrant a monetary theory of business cycles. Indeed, the monetary view of economic fluctuations stands as the principal characteristic of Friedman's extensive research in this area.

To state my own principal conclusion directly, I do not agree with the Friedman and Schwartz appraisal of the importance of money. I find their view of the world fascinating and stimulating, but I am not converted. So far, this rejection stands merely as a testament of my faith. I shall use these comments to explain my misgivings about their theoretical position.

\section{The Money Multiplier}

In effect, Friedman and Schwartz ask me to believe that a \$I billion open market purchase of government securities will raise annual GNP by more than $\$ 20$ billion. The $\$ 1$ billion rise in high-powered money should increase total money by more than $\$ 5$ billion, or more than 2 per cent. (That is my estimate - not that of the authors - but I would not expect serious argument.) In turn, according to the Friedman and Schwartz estimate of 2 for the elasticity of net national product with respect to money, this expansion of the money supply should raise national product by more than 4 per cent - or more than $\$ 20$ billion.

This money multiplier estimate has extremely significant implications for economic policy. It brings monetary policy to the fore and pushes fiscal policy into the background. To see these implications concretely, consider a combined fiscal-monetary action whereby a reduction in personal taxes of $\$ \mathbf{r}$ billion is financed entirely by the creation of new highpowered money. This action may be divided into two steps. The first step consists of a purely fiscal action: taxes are cut by $\$$ I billion and the reduction is financed by an issue of interest-bearing marketable government securities. The second step is then a purely monetary action: the central bank buys the $\$$ I billion of government securities for cash on the open market. The combined multiplieraccelerator effects on GNP of the fiscal action might be estimated anywhere from $\$$ I.5 to $\$ 5$ billion, but nobody's estimate of that step would approach the $\$ 20$ billion attributed to the monetary action, in line with Friedman and Schwartz. To follow them, one must believe 
that the monetary step generates 80 to 90 per cent of the total stimulus in the combined action.

Under typical conditions in the American economy, I would be inclined to reverse the allocation, putting 80 to 90 per cent of the weight on the fiscal step. I should expect a tax rebate that came to its recipients in the form of readily marketable government securities (the equivalent of the purely fiscal action) to be considerably more than half as expansionary as an equal rebate in the form of cash. In the world we inhabit, money substitutes are plentiful and fill the spectrum between money and capital goods. Government securities share many of the properties of cash and few of the characteristics of capital. The form of the increase in the public's net worth (as between money and Treasury securities) seems less vital to aggregate demand than the fact of this increase generated by the fiscal action.

If Friedman and Schwartz are right, the nation is going far astray in current discussions of tax reduction, when we can get all the stimulus we need from moderate shifts in monetary policy toward greater ease. Their verdict on the power of money would not be accepted by the makers of monetary policy, their most ardent critics, or the majority of monetary economists. Even the original architects of quantity theory expected only half as much bang from a new buck when they took proportionality of money and income as a first approximation. The distance of the Friedman and Schwartz position from most professional thinking on stabilization issues does not prove they are wrong. Collective professional judgment has been in error before, but $I$ am orthodox enough to believe that it deserves some credit.

\section{Money and Permanent Income}

The quantitative estimates of large monetary effects on income are vital to the Friedman and Schwartz qualitative view that money accounts substantially for fluctuations in income. Percentage fluctuations in the path of money over cycles are considerably smaller than the percentage variations in income. The relatively stable money variable can be responsible for these wide movements in income, only if money operates on income with great leverage. Friedman and Schwartz account for their large estimates of leverage through the permanent income formulation of the demand for money. The short-run income elasticity of demand for money is found to be low because (I) the demand depends on permanent income, and (2) permanent income varies from year to year by only an estimated one-third as much as aggregate measured income. Then, on the assumption that any imbalance between supply and demand for cash is equilibrated by changes in measured income, a change in the money supply must induce magnified income changes.

If I translate from permanent income to wealth - just because it is a more familiar language to me for some purposes - I can see some point to Friedman's formulation of the demand for money. While I should expect the transactions demand for money to contract along with measured income in a recession, the asset demand for money will not decline so long as wealth is growing. Except for the most severe depressions, wealth in real terms has kept growing through all phases of the cycle. But the market valuation of wealth in portfolios is presumably most important to the asset demand for money, and I doubt that the market value of wealth has fared any better than incomes have in recessions. If my guess on wealth values is correct, I see no reason for a particularly low short-run income elasticity of demand for money.

In Friedman's view, the short-run elasticity is low because transitory income is not used to increase money holdings. Previously, we were told that transitory income does not go into current consumption outlays. I will feel more comfortable about both those propositions when I am told how and where transitory income does get allocated.

In sharp contrast to the low short-run income elasticity of demand for money, their estimate of the long-run elasticity is I.8. I see no logical reasons for money to be such a luxury - with an income elasticity rivalling that of steak - and I am not prepared to accept the finding as a structural characteristic of demand. Since time deposits of commercial 
banks are the component of Friedman and Schwartz money that contributes most to the large coefficient, I wonder whether the result may stem from institutional developments affecting the supply conditions for time deposits by commercial banks.

\section{The Transmission Mechanism}

How does a rise in the money supply increase the level of income? Obviously, people who have been induced to part with an earning asset and to take on cash cannot simply decide to get themselves more income and more wealth in order to restore balance to their portfolios. Some adjustment and transmission mechanism must be involved.

I was surprised to find that the transmission mechanism described by Friedman and Schwartz is so similar to the one I visualize. In their view and mine, money is one ingredient of a general equilibrium theory of asset holdings. Changes in the stock of money will produce waves and ripples that influence the demand for all assets, extending to newly produced goods and services. When the monetary authorities induce people to part with bonds, these people are not really demanding extra cash to hold. They absorb it as a temporary matter before turning to other earning assets. When the resulting expansion in the demand for nonmonetary assets gets reflected in an increased demand for reproducible "capital" and its services, it stimulates either production or prices or both. But there are many links in this chain of asset adjustments running from cash to capital, and I would expect some of them to be rather weak links much of the time.

If monetary factors have the leverage on income that Friedman and Schwartz expect, they must have a better fulcrum than the general equilibrium asset model implies. If I accepted their empirical conclusions, I should be looking carefully at the mechanics of "credit availability." At any time, some firms and households are prevented from acquiring all the goods and services they would like because of their limited ability to borrow. Their portfolios are not in balance and they remain hungry for more capital (or more dissaving).
If an expansion of the money supply channels more funds into the hands of these eager spenders, it can have a large and direct effect on aggregate activity. We do not know that monetary expansion is accompanied by greater ease of credit in this manner, but this disequilibrium mechanism deserves exploration.

\section{The Role of Interest Rates}

The strength of the links in the moneycapital chain depends, in large measure, on the importance of interest rates as equilibrators of portfolios. In relying on the general equilibrium fulcrum, Friedman and Schwartz contend that changes in the rates of return on earning assets do not affect substantially the desired ratio of money to total wealth (or to permanent income). In that case, output and prices are linked rigidly and inexorably to the money supply. The money-income relationship is then the key determinant of the time path of the system, playing the same dominant role as the capital-output relationship does in Harrod's growth model.

If, however, changes in the opportunity cost of holding money can make people hold significantly more cash in their portfolios, the chain is weakened and money is no longer an irresistible force. Over the long run, the economy can move along any one of a large number of possible money-income paths so long as there are compensating changes in rates of return. In the short run, too, changes in yields give flexibility to the economy, preventing the full force of a change in the money supply from impinging on the demand for output. If variations in the prices of earning assets put portfolios back in balance, then the output of capital goods will be less affected by a changing money supply.

The Friedman-Schwartz conclusion on the small role of interest does not rest firmly on either theoretical or empirical evidence. I am not satisfied with their discussion of Latane's results. Latané excludes time deposits of commercial banks from his measure of money; Friedman and Schwartz offer the opinion that different definitions of the money supply may give totally different results on the role of interest rates. They cannot afford to stop 
there. We need to know which set of results offers the more appropriate guide for estimating the economic impact of conventional actions of monetary policy. Furthermore, Friedman and Schwartz seem obliged to explain how time deposits in commercial banks can be a close substitute for demand deposits and yet not be closely substitutable for savings bank deposits, savings and loan shares, and others. This is one example of a repeated puzzle in their analysis: asset prices and returns play a key and oft-cited role in encouraging substitution among nonmonetary earnings assets, but somehow do not influence the demand for those assets which are counted as money.

Nor can I accept the procedures in Friedman's quantitative work on the demand function for money. There, other variables get the first chance to explain demand while interest rates wait in line and are given only the opportunity to eat the leftovers, the residuals of the basic equations. Friedman and Schwartz tell us they are treating money as they would any other stock of assets, such as houses. I feel confident they would give much more prominent treatment to the prices of houses and rental services in estimating demand for that stock than Friedman has given to the opportunity cost of money.

\section{The Direct Link}

The Friedman and Schwartz monetary view of fluctuations is sharply distinguished from the investment approach. Suppose monetary impulses were the principal cause of changes in investment demand and that these investment changes in turn induced fluctuations in consumption and additional responses in investment through a multiplier-accelerator process. Then, economic fluctuation could be equally well described either as a monetary or an investment phenomenon, and presumably would be best described as a money-throughinvestment matter. But they argue that the direct route from money to income offers a more satisfactory explanation than the path that travels from money to interest to investment to income.

In espousing the direct linkage of money to income, Friedman and Schwartz are armed with the powerful empirical results of the Friedman and Meiselman study. There, it was shown that aggregate consumer expenditure has historically been much more closely related to the money supply than to the level of "autonomous expenditures," defined as net private investment plus the government deficit. I have some reservations about the tests, particularly the treatment of the government deficit as autonomous. I also find some of the results puzzling: for example, (I) the "money multiplier" is much smaller than Friedman's other work implies; (2) surprisingly, money explains consumption better than it explains investment. Furthermore, the results may simply mean that changes in the money supply can be rather accurately described as "meeting the needs of trade." With all these lines of defense, I would be less than candid if I dismissed the findings. Had I known what variables were going to be correlated, I would have been willing to bet my nickel on the side that turned out to be the decisive loser. Until and unless there is a satisfactory explanation of these results, the unconverted cannot rest easy.

On the other hand, I doubt that Friedman and Schwartz can feel comfortable with their explanation of the direct linkage. They point out that the direct influence of money extends beyond the items classified as investment in the national accounts, impinging on consumer durable goods, consumer inventories of items classified as nondurable, on the rental services of capital goods, and perhaps on investment in human capital. If it were possible to adjust the national accounts to get a better measure of capital items, this strategy would be indicated. But the current-capital distinction is a blurred one and many items may have both capital and current aspects that defy classification. Hence, in their view, precision may be lost rather than gained by tracing from money to any concept of capital items before moving along to the impact on income.

Certainly, any line separating current from capital items must be a fuzzy one. I share Friedman's view that major consumer durable goods belong in the capital account and do not find them a serious conceptual problem. Elsewhere, the range of fuzziness seems small 
relative to the magnitude of total investment expenditures. The doubtful items listed by Friedman and Meiselman and by Friedman and Schwartz look rather trivial to me. The battle between velocity and the multiplier is most unlikely to turn upon the impact of monetary changes on pantry and boudoir stocks held by households or on private educational expenditures, and even less likely to hinge on the substitution of auto rentals for new car purchases. In general, the difficulties of drawing a line between capital and current outlays seem less serious than those associated with dividing liquid assets between money and nonmoney.

\section{The Cyclical Mechanism}

The monetary cycle outlined by Friedman and Schwartz is monetary both in its impulse and its overshoot mechanism. In their example, which is explicitly not meant to be preclusive, an increase in the money supply starts the fluctuation. The cyclical character of the fluctuation comes from an overshooting monetary cobweb: as prices and incomes adjust to the expansionary impact of the monetary stimulus, people have to scramble back for some of the cash they unloaded initially. Presumably, the authors prefer the double monetary version of the cycle, but it seems worth noting that they could be "half right." Disturbances of a nonmonetary origin could produce cyclical movements through the Friedman and Schwartz monetary cobweb; alternatively, disturbances of a monetary character could be the usual shocks in a world where the overshoot mechanism was not monetary.

At first glance, a monetary explanation of business cycles seems impossible because the money supply does not decline in many cyclical recessions of economic activity. However, Friedman and Schwartz meet this challenge. They advance a monetary accelerator hypothesis whereby a slowdown in growth of the money stock can produce an absolute downturn in income. The workings of the monetary accelerator are not explained lucidly by Friedman and Schwarț. It would have been helpful if they had included a verbal description of a cycle that was initiated by a reduced (but continued positive) growth rate of money.
The following model has some of the characteristics of a monetary accelerator, and I offer it because it may resemble the Friedman and Schwartz view:

I. The stock of money determines the desired stock of capital, in line with some rigid desired portfolio balance.

2. Then, the growth rate of money fixes the growth rate of desired capital.

3. Investment depends on the excess of desired capital over actual capital.

In a moving state of exponential equilibrium, the percentage excess of desired over actual capital must be constant. Now, if the growth rate of money declines, the growth rate of desired capital falls, reducing the excess of desired over actual capital. As a result, investment declines absolutely. This is potentially a cycle model; but, as I see it, the overshoot mechanism lies in the way investment adjusts actual to desired stocks. A slowdown in monetary growth can be the initiator of recession in this world, but it does not look like a double monetary version of the cycle to me. I look forward to a more explicit formulation of the Friedman and Schwartz cycle model in their future work.

\section{Conclusion}

I consider Friedman's works on money a major challenge to the unconverted. They are full of stimulating ideas and significant facts and parameters, and they offer some explanation for all the empirical findings. While I protest against a few of the empirical procedures, the research techniques generally command praise and admiration. I find many of the results and their explanation paradoxical and implausible, yet I cannot really account for them on other grounds. So I feel very uneasy. I wonder whether I can appropriately hold strong intuitive views about relationships and parameters I have never estimated. I wonder, on the other hand, how Friedman can disregard all intuitive evidence.

In reviewing the Friedman and Schwartz paper, I feel as though I am commenting on a highly competent and comprehensive demand study with some astonishing results: coffee and tea are found to be independent commodities while coffee and champagne are 
close substitutes; bus rides have an estimated income elasticity of $\mathrm{r} .8$; the knowledge whether a family owns an auto offers no assistance in explaining its outlays for gasoline. But the values of parameters in aggregative relationships have far more consequence for the direction of economic policy and economic research than any coffee-tea examples. The disciples and the critics of this school of monetary analysis have a social and a scientific responsibility to pursue the issues with intensive empirical and theoretical research.

\section{Clark Warburton, Federal Deposit Insurance Corporation}

The conclusions of Milton Friedman and Anna Schwartz regarding the role of money in business cycles should be no surprise to anyone who has surveyed the history of business-fluctuation theory. The basic cause of the phenomena described by economic writers of the past as financial panics, commercial crises, revulsions, and depressions has been a subject of intense controversy and widely diverse opinions. However, the most continuous thread running through the controversy has been the idea that misbehavior of the monetary and banking system, in the sense of monetary developments or central bank policy inducing contractions in the circulating medium, is the dominant causal element in the generation of business downswings of any substantial size. Also, operations of the banking system in the direction of substantially expanding the stock of money have almost universally been regarded as the basic element in inflationary business booms, and particularly the great inflations of history, recognizing, of course, that exigencies of government finance have been a fundamental force beneath an expansion of the circulating medium in time of war.

The economic literature focusing on changes in the stock of money as the dominant causal force in the generation of major business fluctuations goes back in time throughout and far beyond the ninety years covered by the project on which Friedman and Schwartz are engaged, though no factual study has previously been made covering so long a span of time with such thoroughness and competent analysis. However, the previous literature contains many descriptions by contemporary observers of the sequence of events and of the character of causal relationships. Among these observations is an emphasis on channels of influence which are treated lightly in the authors' sketch of the mechanism transmitting monetary changes. The theory of the impact of changes in the stock of money on business activity, developed over a period of two centuries before publication of the General Theory, recognized the role of changes in interest rates (in the writings of Irving Fisher and Knut Wicksell, for example) but, in general, gave more attention to the process by which successive uses of new units of money coming into the economy had an impact on prices and on business activity, and to the corresponding process when the circulating medium was contracted. In that literature there was also much emphasis upon business anticipations and expectations, related to observed factors influencing or expected to influence the stock of money, such as actual and pending international specie movements, large changes in trade balances likely to have an effect upon such movements, legislation affecting the creation or operations of banks or issue of other forms of circulating medium, and central bank policy announcements. It was recognized that these anticipations and expectations might accelerate or retard - or accentuate - the usual impact of changes in the stock of money on business and consumer decisions, and on some occasions might even give some of these decisions a priority in time over the actual changes in the stock of money.

I would suggest that Friedman and Schwartz's findings regarding the variability of the length of lag between rates of change in the stock of money and in business conditions are likely to be found, upon further examination, to be related to the relative impact, in different cycles, through these various channels. His description of the process by which the initial impact of central bank action, if conducted through open market operations, is concentrated among holders of financial assets and then diffused to the rest of the community is essentially an analysis of lags, under modern monetary and financial arrangements, between 
central bank action designed to stimulate creation of additional units of money, the actual creation of the increments, and receipt of those increments by persons and enterprises who spend them on consumer or capital goods. It is this part of the monetary theory of the origin of business fluctuations, as was brought out in discussions from the floor, that bears some resemblance to what is called Keynesian theory. But when increments to and decrements from the money stock were produced by the banking system without prior action by a central bank, as was the case in the United States during half of the period covered by the Friedman and Schwartz study, the character of the stimulus to the banks and the lags in the process were necessarily somewhat different. This, together with recognition of the role of anticipations and the timing of their impact, suggests that further analysis, with a scrutiny of the circumstances surrounding the various business cycle turning points, might throw much light on the variability in the length of the lag which these authors have found between monetary policy actions and business cycle turning points.

Friedman and Schwartz's estimate of the size of what they call the money multiplier the ratio of the cyclical percentage change in income associated with the percentage change in the stock of money - indicates that the cyclical variation in the income velocity of money is of approximately the same magnitude as the cyclical variation in the stock of money. This conclusion, together with the observed leadership of the change in the stock of money, implies a lag in cyclical changes in velocity behind business cycle peaks and troughs. But surely velocity can hardly lag as far behind the cyclical turning points as the stock of money leads, at least when the latter is measured by the change in the rate of change. Let us hope that Friedman and Schwartz, in their forthcoming volume on trends and cycles in the money stock, will include an analysis of the trends and cycles, particularly the cycles, in income velocity and the timing relationship between such cycles and those in the stock of money. Pursuit of this question should provide a considerable degree of enlightenment on the sequential process and the direction in which causal factors operate throughout the course of business cycles. 